\title{
CADEIA DO BIODIESEL DA BANCADA À INDÚSTRIA: UMA VISÃO GERAL COM PROSPECÇÃO DE TAREFAS E OPORTUNIDADES PARA P\&D\&I
}

\section{Cristina M. Quintella*, Leonardo S. G. Teixeira, Maria Graças A. Korn, Pedro R. Costa Neto", Ednildo A. Torres, Marilu P. Castro} e Carlos A. C. Jesus

Instituto de Química, Universidade Federal da Bahia, Campus de Ondina, 40170-290 Salvador - BA, Brasil

Recebido em 9/1/09; aceito em 5/3/09; publicado na web em 25/3/09

\begin{abstract}
BIODIESEL CHAIN FROM THE LAB BENCH TO THE INDUSTRY: AN OVERVIEW WITH TECHNOLOGY ASSESMENT, R\&D\&I OPPORTUNITIES AND TASKS. Contextualized overview of the Biodiesel Production Chain, from the lab bench to the industry, with critical evaluation of state-of-art and technological development through scientific articles and patents, focusing on feedstock, reaction/production, first and second generation processes, specification and quality, transport, storage, co-products (effluents and sub-products), and emissions. Challenges are identified and solutions are proposed based on the Brazilian feedstock, edaphoclimatic conditions, process monitoring in remote regions, state policy, and environment preservation, among others. Forecasts are made based on the technology assessment, identifying future trends and opportunities for R\&D\&I.
\end{abstract}

Keywords: biofuels production chain; technology assessment; forecasting.

\section{INTRODUÇÃO}

A cadeia produtiva do biodiesel pode ser vista de modo integrado (Figura 1) compreendendo matérias- primas e insumos, reação (transformação), processo de produção e purificação, controle de qualidade, transporte, armazenamento e estocagem, coprodutos (efluentes e subprodutos), uso e emissões. A Química permeia toda a cadeia do biodiesel, sendo indispensável para sua viabilização econômica, ambiental e tecnológica, tanto nas áreas rurais como industriais.

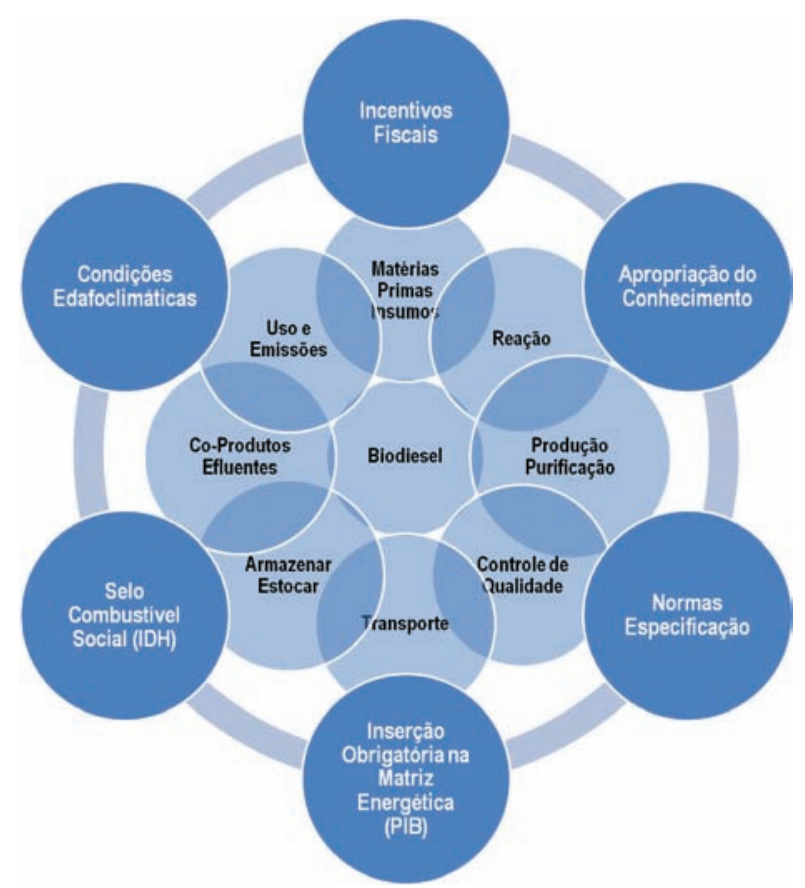

Figura 1. Cadeia produtiva do biodiesel: $P \& D \& I$ e seu entorno com o arcabouço legal e econômico

*e-mail: cristina@ufba.br

"Prof.da Universidade Tecnológica Federal do Paraná atuando como Pesquisador Visitante na Universidade Federal da Bahia.
A busca pela inserção do biodiesel na matriz energética tem sido um dos focos de vários países e blocos comerciais. ${ }^{1-4}$ Esta intensificação do uso do biodiesel se alicerça num tripé: (1) ambiente (melhoria das condições climáticas por redução das emissões e utilização de $\mathrm{CO}_{2}$ pela matéria-prima); (2) social (desenvolvimento rural associado à produção de matéria-prima); (3) energia (independência de fornecedores, consumidores produzindo sua própria energia).

Para que o biodiesel seja classificado como fonte renovável de energia é essencial considerar não só o balanço de energia da sua produção, mas também as proporções de energia alocadas aos seus coprodutos e ao seu reaproveitamento. ${ }^{5}$ Além de renovável, o biodiesel tem ainda a vantagem de redução das emissões reguladas. Adicionalmente, permite melhorar o fechamento do ciclo do carbono (carbon neutral) e, quando de origem vegetal, intensifica o sequestro de $\mathrm{CO}_{2}$ da atmosfera, impactando favoravelmente nas mudanças climáticas do planeta, ao retirar $\mathrm{CO}_{2}$ no crescimento das plantas geradoras de óleo, deste modo compensando a adição de $\mathrm{CO}_{2}$ à atmosfera durante a sua queima. O biodiesel é ainda biodegradável e, adicionado ao diesel, tem efeito sinérgico de biodegradação por cometabolismo. ${ }^{5}$

A maior desvantagem tecnológica do biodiesel é a relação inversa entre a estabilidade oxidativa (favorecida pela maior concentração de ácidos graxos saturados) e as propriedades a baixa temperatura, como ponto de névoa e ponto de entupimento (favorecidos pela maior concentração de ácidos graxos insaturados). ${ }^{6}$

Economicamente, para que o biodiesel tenha um papel ativo no mercado de energia, sendo mais do que um aditivo, precisa ser produzido a um custo bem mais baixo e atender às especificações brasileiras e internacionais.

Adicionalmente, para que a cadeia do biodiesel gere produto interno bruto (PIB) e melhore o índice de desenvolvimento humano (IDH), é necessário que esteja alicerçada numa política de Estado envolvendo aspectos econômico-financeiros, incentivos fiscais e vantagens econômicas, além de aspectos legais como normas e especificações, obrigatoriedade de inserção na matriz energética e apropriação do conhecimento através de propriedade industrial por patentes.

A dimensão do mercado no Brasil e no planeta assegura grande oportunidade para o setor agrícola, potencializando que milhares de famílias brasileiras sejam beneficiadas (principalmente as do semi- 
árido brasileiro), com o aumento de renda proveniente do cultivo e comercialização dos óleos obtidos das plantas oleaginosas e utilizados na produção do biodiesel.

Dentre os países que adotaram o biodiesel como componente obrigatório de sua matriz energética, o Brasil vem, de forma pró-ativa e coerente, realizando o que planejou, sendo um exemplo do alto potencial da realização efetiva da política de Estado. ${ }^{4}$

A prospecção tecnológica tem contribuído significativamente na geração de políticas de longo termo, de estratégias e de planos, e na fundamentação nos processos de tomada de decisão referentes à pesquisa, ao desenvolvimento e à inovação $(\mathrm{P} \& D \& \mathrm{I}) .{ }^{7}$ Ela utiliza essencialmente patentes e artigos que não só são o depositório do conhecimento especializado, ${ }^{8}$ como alicerçam legalmente a economia. Em artigos, o conhecimento passa a ser de domínio público e qualquer um o pode utilizar para comercializar e produzir. Sob a forma de patentes, o conhecimento pode contribuir mais efetivamente para o PIB e o IDH, especialmente nos casos em que P\&D\&I são financiados com recursos públicos de um país, permitindo que os resultados revertam para esse mesmo país durante os anos iniciais. Assim, é em geral recomendável que, primeiro, a patente seja depositada e, após essa data, seja então submetido o artigo. O Instituto Nacional de Propriedade Industrial do Brasil (INPI) recentemente iniciou um sistema de Alertas Tecnológicos, ${ }^{9}$ para divulgar pedidos de patentes publicados internacionalmente, referentes a campos específicos, tendo recentemente lançado um sobre biodiesel.

O objetivo deste trabalho é, através da prospecção tecnológica, identificar gargalos científicos e tecnológicos na cadeia produtiva do biodiesel e suas respectivas oportunidades, propondo ações de P\&D\&I, com contribuição expressiva da Química, que possam melhorar a qualidade de vida da população, especialmente no Brasil. Para isso, foram consultados bancos de artigos e de patentes, sendo os resultados avaliados à luz das condições específicas do território brasileiro, da pesquisa e desenvolvimento (P\&D), da ciência e tecnologia (C\&T), da indústria e do arcabouço legal brasileiros.

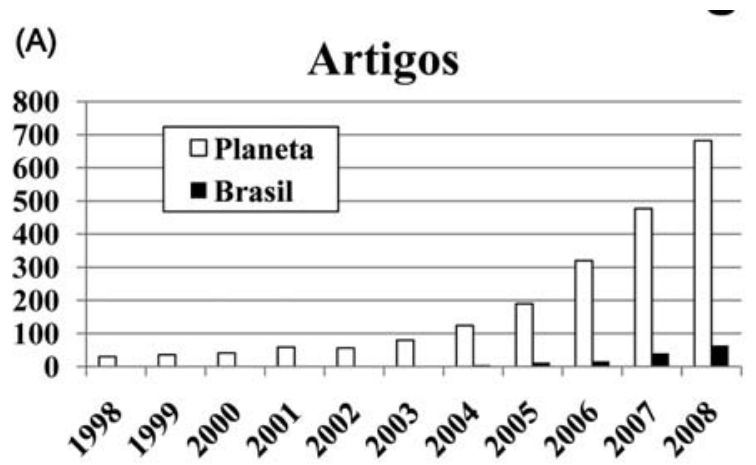

(C)

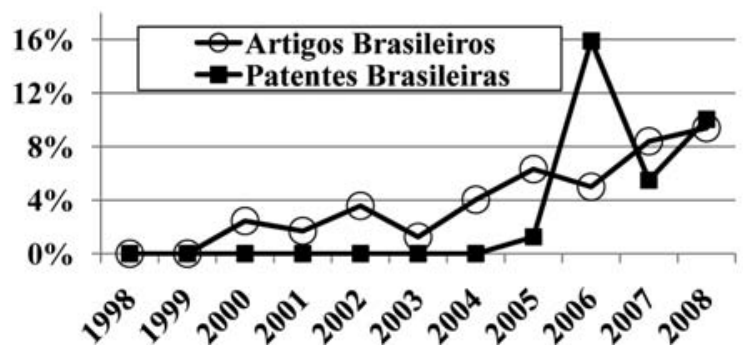

Este trabalho está dividido em: (1) panorama geral de artigos e patentes em biodiesel; (2) reação e produção; (3) política de estado e resposta empresarial; (4) condições edafoclimáticas no Brasil; (5) matéria-prima; (6) álcoois; (7) qualidade e especificação; (8) aditivos e misturas (blends); (9) armazenamento e estabilidade; (10) emissões; (11) coprodutos e, (12) perspectivas.

\section{PANORAMA GERAL DE ARTIGOS E PATENTES EM BIODIESEL}

O escopo da estratégia de pesquisa visou garantir que a maior parte das patentes e dos artigos em cada elo da cadeia produtiva do biodiesel fosse localizada e processada. A busca por códigos de patentes mostrouse inadequada, pois não focava no tema biodiesel que é transversal e está presente em todas as classes. A associação de códigos e palavras chave excluía patentes de interesse. Assim, foi adotada uma estratégia semelhante à definida em janeiro de $2006,{ }^{10}$ com 〈biodiese*> no resumo ou no título. A pesquisa utilizou dois indicadores de data: prioridade e publicação. Quando não explicitado neste trabalho, é utilizada a data de publicação. Os códigos processados foram os do Sistema de Classificação do Escritório Europeu de Patentes (ECLA).

As bases de patentes do INPI e do United States Patent and Trademark Office (USPTO) apresentaram poucas patentes devido a conterem apenas os depósitos nos escritórios brasileiro e norte americano, respectivamente. Das bases que importam regularmente os dados de diversas outras bases e/ou homepages, foi escolhida a European Patent Office (EPO) por ter menos repetições, melhor cobertura e permitir avaliar por códigos ECLA. ${ }^{11}$ Já as bases Scopus e Derwent Innovations Index (Derwent) apresentaram, respectivamente, diversas repetições e escopo limitado. . $^{12,13}$

As evoluções anuais de artigos e patentes (Figuras 2A e B) apresentam curvas exponenciais com padrão de tecnologia emergente, mostrando ser uma área ainda competitiva em termos de pesquisa científica e da apropriação do conhecimento por patentes.

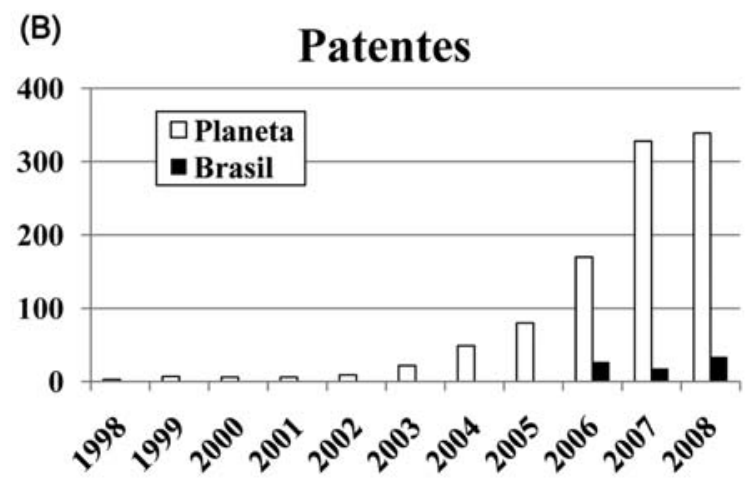

(D)

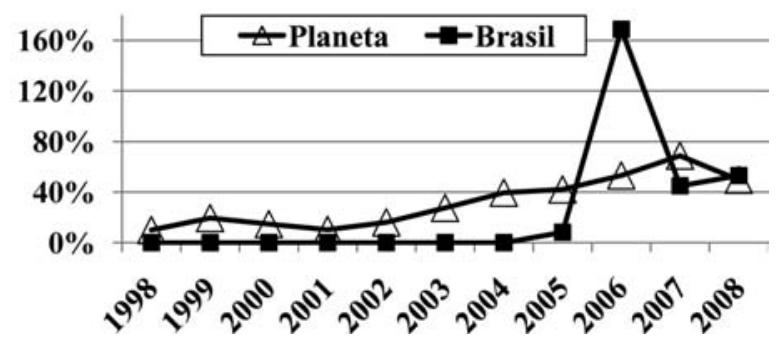

Figura 2. Evolução anual de: (A) número de artigos; (B) número de patentes; (C) percentual de patentes e de artigos brasileiros; $(D)$ percentual de patentes em relação a artigos no planeta e no Brasil 
Das patentes ainda vigentes, a primeira foi requerida em 1989 por Wimmer Theodor, da Áustria, e foca a etapa de purificação por lavagem ácida da glicerina bruta (GB), coproduto do biodiesel obtido por transesterificação. ${ }^{14}$

No Brasil, a primeira patente de brasileiros, identificada por esta busca, foi requerida em 11/09/2003 e trata de biocatalisadores enzimáticos encapsulados. ${ }^{15} \mathrm{O}$ primeiro artigo publicado por brasileiros, identificado por esta busca, data de 2000 e relata a produção de biodiesel a partir de óleo de fritura. ${ }^{16}$

Em biodiesel, o percentual de artigos oriundos do Brasil (Figura 2C) é superior à média anual brasileira desde 2000, crescendo sensivelmente a cada ano, mostrando que a participação da ciência brasileira neste tema tem se firmado em nível internacional a uma taxa superior à da média científica brasileira. $\mathrm{O}$ percentual de patentes brasileira só deve ser avaliado após 2005, quando o Brasil começa a apropriar com mais continuidade, sendo que o pico de 2006 e a queda em 2007 parecem indicar que ainda é necessário que a cultura de apropriação se torne mais regular, ou seja, não só mais difundida como, também, mais valorizada e exigida pelas agências de fomento brasileiras e pelo Estado Brasileiro.

A razão anual entre o número de patentes e de artigos do planeta (Figura 2D) mantém-se baixa de 1998 a 2002. Esse quinquênio compreendeu a etapa de acúmulo de conhecimento, ainda sem consciência do que poderia e de como deveria ser apropriado sob a forma de patentes. Seguidamente veio a fase de elevação de depósitos de patentes, correspondendo à maturação da visão de desenvolvimento tecnológico, típica de uma tecnologia emergente e com potencial futuro, sendo ainda reforçada pelo grande interesse internacional em biocombustíveis e pelo crescimento da consciência de preservação do planeta. Ainda não foi atingido um patamar estável, evidenciando que a tecnologia é realmente emergente, tendo ainda alta potencialidade de desenvolvimento tecnológico. No caso do Brasil, esta razão apresenta flutuações tendo um máximo em 2006 (170\%), caindo logo a seguir em 2007 (45\%), e tendendo a se igualar ao percentual do planeta em 2008. Isto pode ser atribuído à existência de demanda reprimida de depósitos de patentes que foi liberada em 2006, seja pela consciência do que poderia e deveria ser depositado e pela facilidade de arcabouço legal com a Lei da Inovação (no. 10.973 de 2/12/04) e sua regulamentação (Decreto no. 5.563, de 11/10/05), seja porque a cultura de patentear está em seus primeiros anos de disseminação e não atingiu ainda um patamar estável.

No grupo dos países que apenas têm publicado artigos (Figura 3A) destacam-se a Índia, Turquia, Espanha, Itália e Coréia. Dentre os países que geram conhecimento cientifico e apropriam o desenvolvimento tecnológico (Figura 3B) destacam-se os Estados Unidos da América (EUA), seguidos por China, Brasil, Japão, Canadá, Coréia do Sul, Alemanha e Reino Unido (UK). Cerca de 18\% da apropriação é feita pelos EUA, percentual que é inferior ao percentual global de patentes dos EUA, mostrando que, apesar dos EUA terem a liderança numérica neste início de desenvolvimento tecnológico, é possível que outros países possam vir a repartir essa liderança como ocorreu anteriormente com o Japão em chá verde, erva doce e biossurfactantes, com a Espanha em extratos vegetais aplicados a cosméticos e com o Reino Unido em óleo de algodão para a área de saúde e fluorescência de petróleo. ${ }^{17}$ Dentre os países que mais depositam patentes (Figura 3C), a China apresenta o maior percentual de patentes em relação a artigos, evidenciando uma postura agressiva na apropriação de conhecimento e da tecnologia, sendo seguida por Coréia do Sul, Brasil, Canadá e EUA. O Brasil, em 2006, ${ }^{10}$ estava na oitava posição em artigos e na terceira posição em patentes, parecendo evidenciar a preocupação maior de proteger o conhecimento antes de sua divulgação sob a forma de artigos. No entanto, em 2008 o Brasil encontra-se em terceiro lugar, tanto em artigos como em patentes. Este fato é preocupante, pois pode indicar que as políticas brasileiras estão incentivando mais publicação do que apropriação neste tema, podendo levar à divulgação indiscriminada da $C \& T \& I$ desenvolvida no Brasil sem preocupação com apropriação. Isto pode ser um reflexo das agências de fomento brasileiras (CNPq, CAPES, FAPs, FINEP etc.) não considerarem ainda depósitos de patentes de um modo similar aos artigos em suas avaliações de produtividade, qualidade e mérito. A evolução anual de artigos para cada país apresentou crescimento exponencial anual para os oito países que mais publicam. Já em patentes, observa-se crescimento exponencial apenas para os EUA. A China é uma entrante, tendo começado o depósito expressivo de patentes apenas em 2006, e os demais países apresentam irregularidade em seus depósitos. O percentual anual de patentes em relação a artigos mantém-se praticamente constante em até 70\% para os EUA, Alemanha e UK, evidenciando a cultura já bem estabelecida de apropriação do conhecimento destes países. Nos demais países, o percentual flutua mostrando que ainda estão nos anos iniciais de apropriação, destacando-se os picos em 2005 da Coréia do Sul (550\%) e do Canadá (270\%), e em 2007 da China (200\%).

$\mathrm{O}$ percentual de patentes requeridas internacionalmente pelo Patent Cooperation Treaty (PCT) na World Intellectual Property Organization (WIPO) caiu de 30 para 22\% entre janeiro de 2006 e novembro de 2008 (Figura 4A) ${ }^{10}$ Isto pode ser atribuído tanto à
(A)

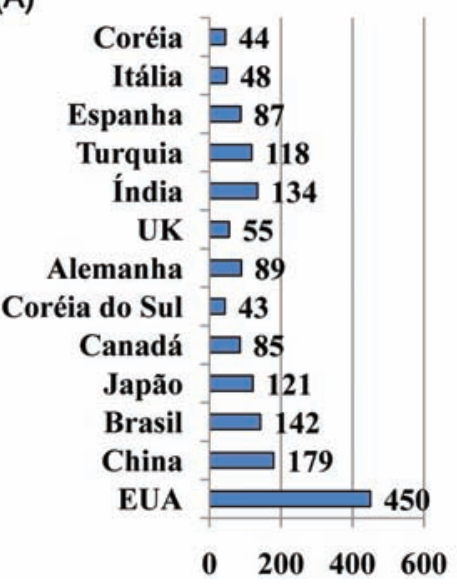

(B)

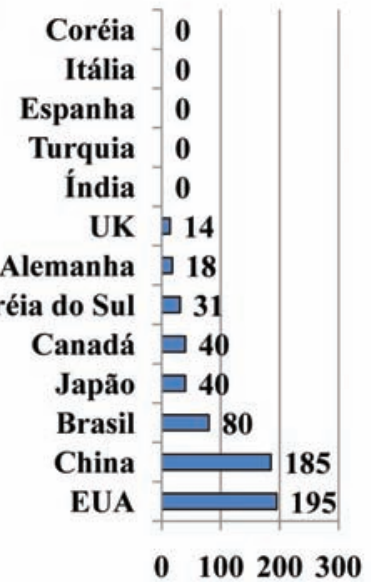

(C)

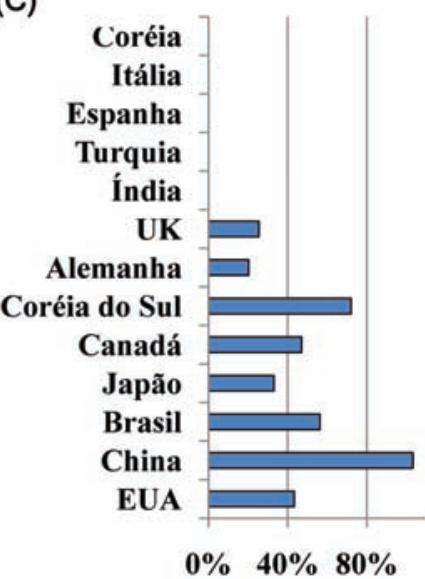

Figura 3. Países detentores do conhecimento científico e do desenvolvimento tecnológico: (A) artigos; (B) patentes; (C) percentual de patentes em relação a artigos 
decisão dos países de proteger, principalmente no seu território nacional, a tecnologia que desenvolveram, devido à grande dependência do biodiesel com o tipo de insumos utilizados, logística e custo de transporte, como à falta de cultura de proteção patentária internacional (know-how e recursos financeiros). No caso do Brasil, $18 \%$ das patentes depositadas no INPI solicitaram PCT, sendo que nenhuma delas é oriunda do Brasil, evidenciando não só que os outros países estão considerando o Brasil como um país com grande potencial de desenvolvimento de tecnologia de biodiesel e de produção e comercialização, como também têm interesse de licenciar a sua tecnologia no Brasil. A ausência de patentes oriundas do Brasil com PCT pode ser atribuída ou ao Brasil não estar preocupado em exportar sua tecnologia, ou ainda à incipiência da cultura de depósito de patentes. Esta estratégia brasileira pode ser perigosa, pois apenas o território brasileiro fica restrito para produção e comercialização, podendo a tecnologia desenvolvida pelo Brasil ser utilizada em qualquer outro país como domínio público.

\section{(A) Depósitos Internacionais}

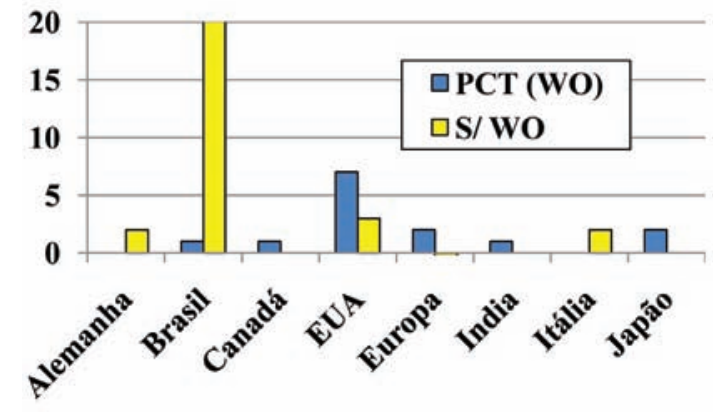

(B)

Patentes no Brasil

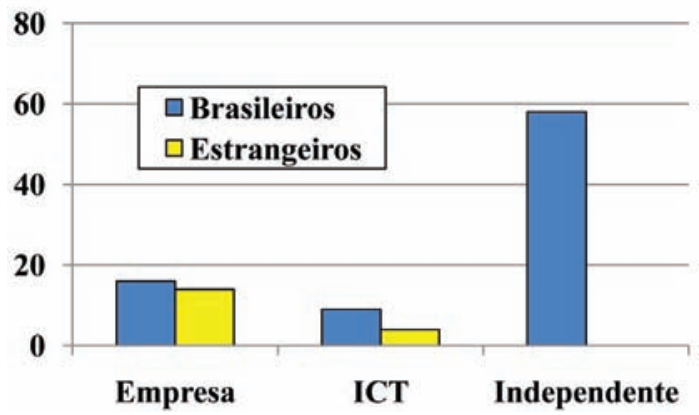

Figura 4. Patentes depositadas pelos países no INPI: (A) com e sem PCT; (B) por tipo de depositante (empresa, instituição de ciência e tecnologia ICT e inventores independentes, especificando os depósitos por brasileiros e por não brasileiros

Em janeiro de 2006, ${ }^{10}$ os depositantes das patentes eram $44 \%$ empresas, 39\% inventores independentes e 19\% Instituições de Ciência e Tecnologia (ICTs). No caso do Brasil, eram 42, 48 e $10 \%$, respectivamente, para empresas, independentes e ICTs, sendo que as empresas que mais detinham patentes eram dos EUA: Stepan Co. e Renessen LLC. Em novembro de 2008, no Brasil (Figura 4B), os depositantes de patentes foram $28 \%$ empresas, $59 \%$ independentes e $13 \%$ ICTs. Houve um aumento significativo de depósitos de independentes, sendo todos de nacionalidade brasileira. Este grande percentual pode ser atribuído à falta de tradição das ICTs do Brasil em apropriação do conhecimento através de patentes, aliada ao fato de que cerca de $80 \%$ dos recursos humanos geradores de desenvolvimento tecnológico se encontrem atuando nas ICTs, ${ }^{18} \mathrm{o}$ que levou a iniciativas individuais. Foram identificados 211 inventores nas patentes depositadas no Brasil, sendo que 1 participa de 3 patentes, 10 participam de 2 patentes e os demais participam apenas de 1 patente, evidenciando que ainda não existe nenhum inventor brasileiro que seja destacado em número de patentes. Isto, apesar de evidenciar a incipiência do desenvolvimento tecnológico no Brasil, é também bastante promissor, pois existe um número grande de pesquisadores envolvidos com o tema, podendo ser a massa crítica necessária para o Brasil crescer em apropriação na cadeia produtiva do biodiesel.

Das 27 empresas que depositaram no Brasil, têm mais patentes a Petrobras, a Stepan Co., a Fast Ind. Com. e a Degusa. A maioria é dos EUA, tendo também empresas da Alemanha, Índia, Itália e Japão. O percentual expressivo das empresas estrangeiras que depositam no Brasil confirma que o Brasil se tornou um território interessante para restringir comercialização e fabricação de biodiesel, o que era de se esperar pela coerência e continuidade da política de Estado para o biodiesel.

Das ICTs que depositam no Brasil (Figura 4B) 79\% são brasileiras (UNICAMP, UFRJ, UFPR, UFBA e IME), sendo as estrangeiras as universidades de Carnegie Mellon (EUA), Mississippi (EUA) e Tsinghua (China).

Os artigos foram publicados em 432 revistas, principalmente Energy \& Fuels, Fuel, Journal of the American Oil Chemists Society e Bioresource Technology (Figura 5A). A Química Nova e o Journal of the Brazilian Chemical Society publicaram 19 e 5 artigos, respectivamente, compreendendo $17 \%$ dos artigos de autores brasileiros. Os autores com mais artigos (Figura 5B) são A. Demirbas (Turquia) em visão geral, gestão e estratégia; Marc. A. Dube (Canadá) em reação, separação e uso; Wei Du (China) em microbiologia e biocatálise; Dehua Liu (China) em produção; Breda Kegl (Eslovênia) em combustão e, Paulo A. Z. Suarez (Brasil) em catálise.

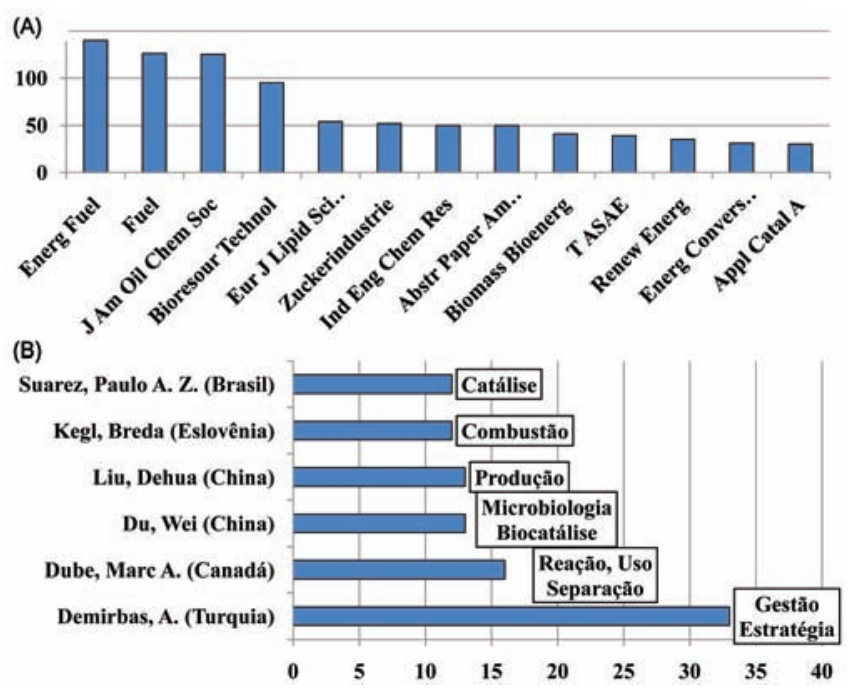

Figura 5. (A) Revistas indexadas com mais artigos, (B) autores que mais publicam

Cada patente, ao ser depositada, recebe pelo menos dois códigos referentes a constituição e uso, cujos significados podem ser obtidos em inglês na EPO e em português no INPI. ${ }^{19,20}$ Os códigos mais utilizados no planeta (Figura 6) são os das seções C - Química, Metalurgia (84\%); B - Operações de Processamento, Transporte (9\%) e, A - Necessidades Humanas (4\%). Nas patentes brasileiras, esta proporção é de 47, 22 e 9\%, respectivamente, para C, B e A, tendo ainda $13 \%$ na seção $\mathrm{G}$ - Física. A alta contribuição do Brasil para o grupo $\mathrm{G}$ se deve à intensa atuação brasileira em qualidade de biodiesel com diversos métodos espectroscópicos, utilizando os códigos (IPC1-7): G01N21/25, (IPC1-7): G01N33/26, G01J3/42, 

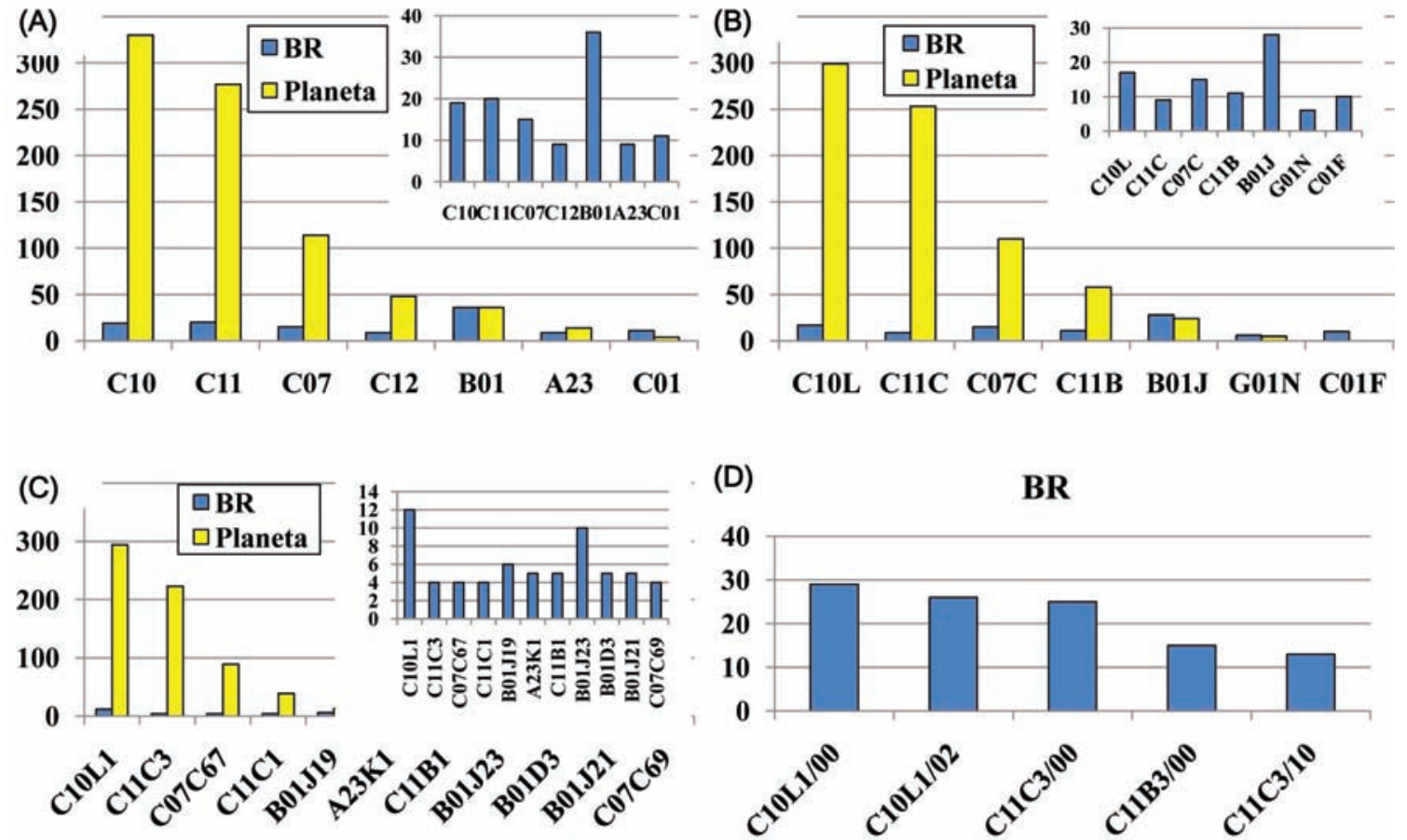

Figura 6. Número de patentes segundo a classificação ECLA de patentes mais utilizadas. (A) seções; (B) subseções; (C) grupos; (D) subgrupos

G01N21/31, G01N21/35, G01N21/77, G01N31/22, G01N33/26, G01N33/28 e G05B19/05.

Comparando os códigos mais utilizados do planeta e do Brasil (Figura 6), o Brasil tem proporcionalmente mais patentes em B01 (processos ou aparelhos físicos ou químicos em geral) concentradas em B01J23 (catalisadores compreendendo metais ou óxidos ou hidróxidos de metais não incluídos no grupo), B01D3 (destilação ou processo de troca correlatos, nos quais os líquidos estão em contato com meios gasosos, por exemplo, extração) e B01J21 (catalisadores compreendendo os elementos, os óxidos ou hidróxidos de magnésio, boro, alumínio, carbono, silício, titânio, zircônio e háfnio). Isto mostra que a maior parte das apropriações brasileiras foca as etapas de reação, separação e purificação, especialmente as associadas à tradicional obtenção de biodiesel através de transesterificação.

Os subgrupos mais utilizados pelo Brasil (Figura 6D) referemse à matéria-prima (gorduras, óleos, ou ácidos graxos), produção de biodiesel especialmente por transesterificação e utilização como combustível.

Todos os itens da cadeia produtiva do biodiesel têm mais artigos do que patentes (Figuras 7 e 8). Os artigos (Figura 7) focam mais a produção, seguidas do processo e da reação, enquanto que nas patentes o processo é mais focado do que a produção. ${ }^{21}$ Isto era de se esperar, considerando que o tema dominante é a reação de transesterificação, que é bem conhecida e de domínio público, e que a inovação nos processos de produção de biodiesel pode variar bastante. No caso do Brasil, são também encontradas bastantes patentes referentes a processos para garantia da qualidade, como aditivação, armazenamento, desidratação e diluição.

\section{REAÇÃO E PRODUÇÃ̃o}

O uso direto de óleos vegetais e animais como combustível foi superado pelo uso de óleo diesel derivado de petróleo, tanto por fatores econômicos quanto técnicos. A utilização direta do óleo in natura pode causar danos aos motores de ciclo diesel como ocorrência de excessivos depósitos de carbono, obstrução nos filtros de óleo e bicos injetores, diluição parcial do combustível no lubrificante e comprometimento da durabilidade do motor. ${ }^{3,22}$ Microemulsões foram também avaliadas para uso em injetores, sendo compostas por diesel, óleo vegetal, álcool como metanol, etanol ou propanol (aditivo para baixar a viscosidade), surfactante (álcoois maiores) e aditivo (nitratos alquílicos) para melhorar o número de cetanos. ${ }^{23} \mathrm{As}$ características do spray gerado, quando se utilizam as microemulsões, propiciam melhoria do desempenho, no entanto, o uso prolongado causa entupimento no injetor, depósitos de carbono e combustão incompleta, reduzindo a qualidade das emissões e a quantidade de energia gerada.

A produção de biodiesel pode ser por processos de $1^{\mathrm{a}}$ ou de $2^{\mathrm{a}}$ geração. ${ }^{24}$ Para ambos, os custos repassados são mais altos do que os da gasolina e do óleo diesel, sendo necessários subsídios para que sejam competitivos.

A maioria das plantas industriais utiliza processos de $1^{\text {a }}$ geração para produção de biodiesel, sendo que duas rotas principais são utilizadas. Na primeira, o biodiesel é produzido pelo processo de transesterificação, também conhecido como alcoólise, de triacilglicerídeos de origem vegetal e animal, sendo obtida uma mistura de ésteres de ácidos graxos, cuja estrutura molecular apresenta enorme semelhança físico-química com o óleo diesel mineral. ${ }^{25} \mathrm{O}$ processo de transesterificação consiste em uma sequência de três reações reversíveis e consecutivas, em que os monoacilglicerídeos e os diacilglicerídeos são os intermediários. Outra rota é aquela conhecida por esterificação, na qual um ácido graxo reage com um mono-álcool de cadeia curta, também na presença de catalisador, dando origem a monoésteres de ácidos graxos. ${ }^{4}$ Normalmente, a escolha pela transesterificação ou esterificação é definida pelas características da matéria-prima, principalmente no que se refere ao teor de ácidos graxos livres. Processos envolvendo etapas de esterificação e transesterificação em sequência também podem ser utilizados. Para matérias-primas onde o teor de ácidos graxos é elevado, por exemplo, uma etapa prévia de reação para esterificação dos ácidos graxos pode ser conduzida utilizando a catálise ácida, seguida de uma etapa de transesterificação. ${ }^{26}$ Recentemente, a preocupação com a divulgação destes processos levou à publicação de rotinas laboratoriais passíveis de serem utilizadas no ensino, visando a formação de recursos humanos. ${ }^{27}$ 
(A)

$$
\text { 口patentes } \square \text { artigos }
$$

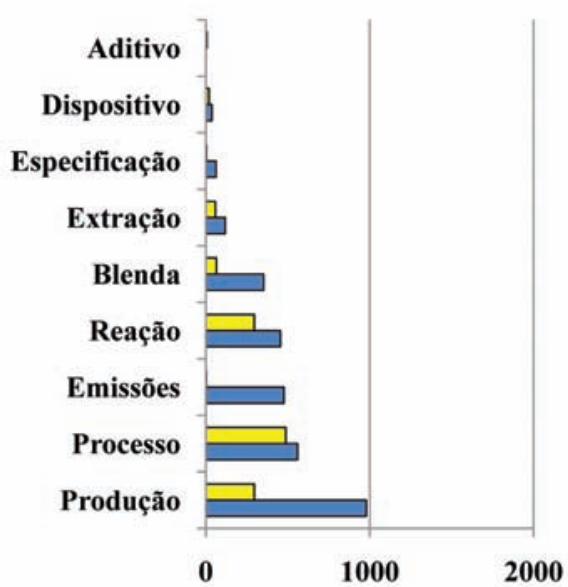

(C)

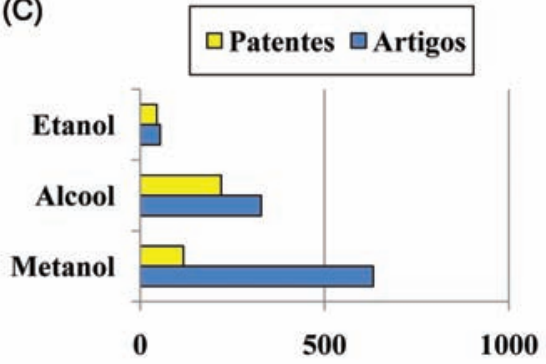

(B) $\square$ Patentes $\square$ Artigos
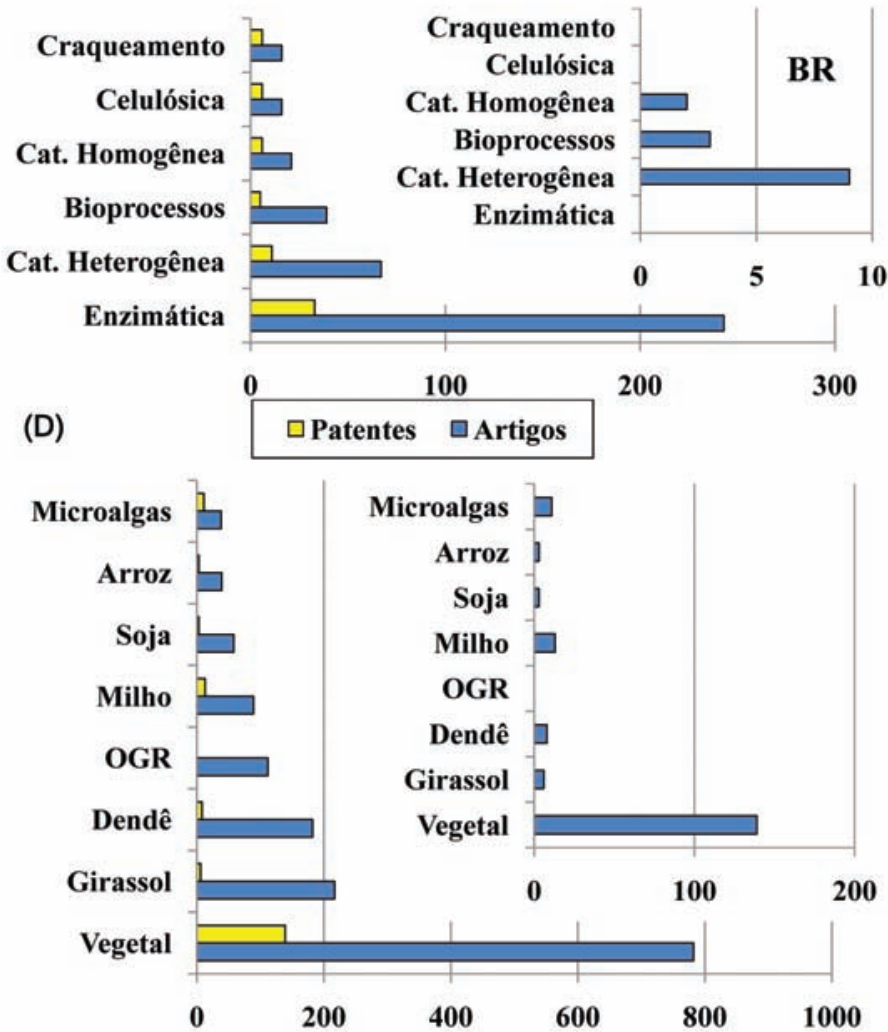

Figura 7. Patentes e artigos por (A) tema; (B) processo de produção de biodiesel, mostrando detalhe com as patentes brasileiras; (C) álcoois; (D) óleos, mostrando detalhe com as patentes brasileiras

(A) Patentes - Temas BR

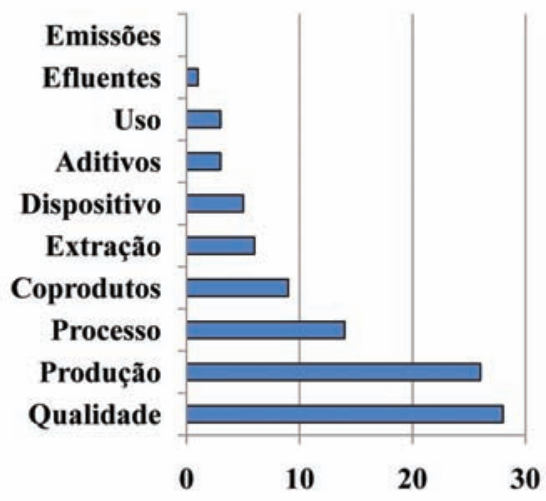

(C) Patentes -Coprodutos BR

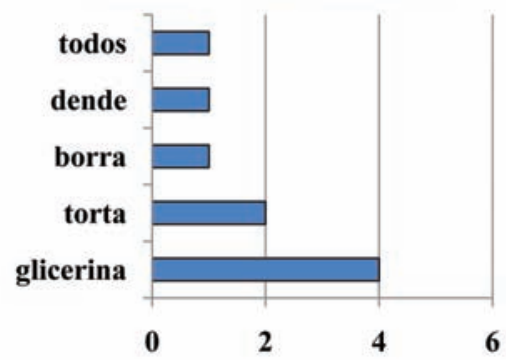

(B)

Patentes - Dispositivos BR

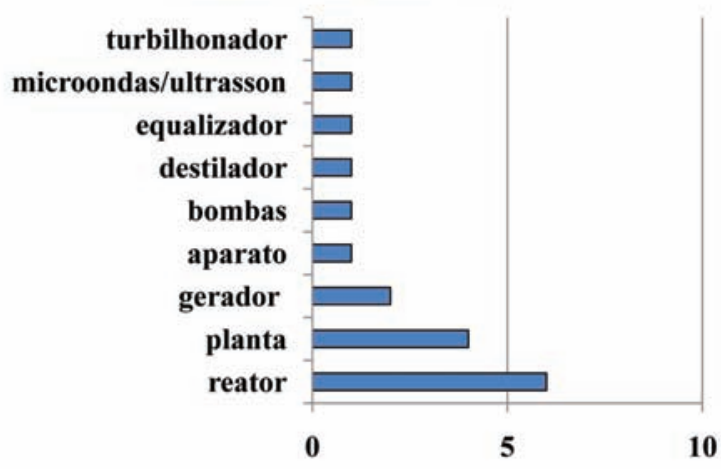

(D)

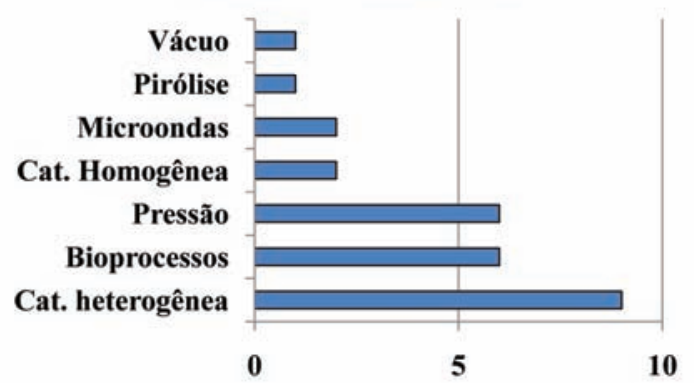

Figura 8. Patentes brasileiras por (A) tema; (B) processo de produção de biodiesel; (C) álcoois; (D) óleos 
A separação e purificação eficientes são importantes para a estabilidade do biodiesel, sendo necessários novos e melhores métodos de separação do produto obtido a partir de matérias-primas brasileiras, de modo a melhorar a eficiência do processo, baixando o preço final e melhorando a qualidade como, por exemplo, processos baseados em uso de argilas adsorvedoras. ${ }^{28}$

Os catalisadores para transesterificação podem ser ácidos, básicos ou enzimáticos, além de poderem ser homogêneos ou heterogêneos. ${ }^{23,29}$

Os catalisadores homogêneos básicos $(\mathrm{NaOH}, \mathrm{KOH}$ etc.) são mais utilizados por terem maior eficiência e menor corrosividade, taxa de reação relativamente alta mesmo a baixas temperaturas ( 60 $\left.{ }^{\circ} \mathrm{C}\right)$ e custo relativamente baixo. ${ }^{3,23}$ Inicialmente são adicionados ao álcool e, depois, tem lugar a reação com o óleo, formando biodiesel e GB. O processo de purificação do biodiesel não é simples, devido à contaminação por glicerina residual, mono, di e triacilglicerídeos, sabões formados pela reação entre o catalisador e matérias graxas, além de contaminação por água., ${ }^{3,23,30}$ Tais contaminantes geram problemas sérios nos motores do ciclo diesel, como corrosão ou formação de incrustações, exigindo purificação cuidadosa e aumentando os custos da produção, além de gerarem efluentes com impacto ambiental negativo.

A catálise homogênea ácida é indicada quando a matéria-prima apresenta acidez elevada, ou seja, quando o óleo tem teor de ácido graxo livre mais elevado e maior conteúdo de água, pois estes ácidos reagem com o catalisador básico, destruindo-o e gerando sabões. ${ }^{31}$ Os ácidos mais comumente utilizados são sulfúrico, fosfórico, clorídrico ou sulfônico orgânico. ${ }^{32} \mathrm{O}$ rendimento obtido com a catálise ácida é alto, no entanto, os ácidos podem corroer os recipientes e vasos, e a taxa de reação é lenta. ${ }^{32}$ Assim, estudos que busquem procedimentos com melhores conversões e materiais resistentes ao meio reacional são boas oportunidades para P\&D\&I.

Na catálise heterogênea, os catalisadores (óxido de cálcio, óxido de magnésio, zircônio - alumínio - titânio - zircônio dopado com potássio, entre outros) são mais facilmente removidos da mistura reacional, podendo minimizar os problemas ambientais, facilitando a reutilização do catalisador através de sua regeneração. ${ }^{33,34}$ Entretanto, é ainda necessário minimizar a exaustão do catalisador, obter maiores taxas de conversão, reduzir a quantidade de catalisador para viabilização econômica, ${ }^{6,35}$ reduzir a lixiviação dos catalisadores e avaliar os impactos da presença de seus resíduos na qualidade dos produtos e dos efluentes na qualidade ambiental.

A produção enzimática de biodiesel, relatada usualmente com lipases, tem a vantagem de obtenção de biodiesel com maior pureza, uma vez que o processo permite uma separação mais fácil de seu coproduto, a GB. ${ }^{2}$ No entanto, as enzimas não podem ser reutilizadas, tornando-se uma barreira econômica para a produção comercial. Uma solução é a imobilização da enzima (intracelular ou extracelular) num suporte que pode ser de biomassa, mas a sua atividade é inibida pela presença de metanol e de GB da mistura reacional. É possível evitar a desativação da enzima com o uso de terc-butanol (solvente comum a óleo e metanol), a remoção contínua da GB produzida por diálise ou por extração por solvente e, a adição progressiva de metanol mantendo sua concentração sempre baixa no meio. ${ }^{2,15,36}$

A transesterificação sem catalisador utilizando álcool supercrítico aumenta o custo do biodiesel devido à grande energia necessária. ${ }^{6} \mathrm{~A}$ eficiência do processo aumenta se for realizada na presença de óxido de cálcio. ${ }^{37} \mathrm{~A}$ faixa de temperatura também é crítica, pois abaixo de $350{ }^{\circ} \mathrm{C}$ o rendimento é muito baixo e acima de $400{ }^{\circ} \mathrm{C}$ ocorre a degradação térmica dos ésteres. ${ }^{37}$

Outros processos alternativos para a obtenção de biodiesel através da reação de transesterificação, independentes ou associados, têm sido investigados com o objetivo de aumentar o rendimento, reduzir o tempo de reação e diminuir o consumo de reagentes e os impactos ambientais, ${ }^{26}$ como o uso de energia de micro-ondas ${ }^{38,39} \mathrm{e}$ da irradiação ultrassônica. ${ }^{39,40}$

Os processos de $2^{\text {a }}$ geração mais comuns partem da biomassa lignocelulósica e, através de pirólise ou de liquefação hidrotérmica, produzem o bio-óleo que passa por hidrotratamento e refino, gerando o biodiesel. Ao final são necessários procedimentos de tratamento do óleo obtido. Usualmente, ocorrem na presença de catalisadores e causam mudanças de composição química devido à exposição à alta temperatura, gerando produtos de menor viscosidade e com maior número de cetanos. No entanto, têm as desvantagens de utilizar equipamentos de alto custo e requerer separação por destilação das diversas frações. Esta tecnologia ainda é cara e embrionária, estando mais avançada para produção do etanol do que para biodiesel.

Um dos processos desenvolvidos é o H-BIO da Petrobras para obtenção do chamado diesel verde que, apesar de não ser biodiesel especificamente, consiste num produto híbrido com características físico-químicas semelhantes às do óleo diesel mineral, com menor impacto ao meio ambiente, renovável e com ciclo fechado de emissões dos gases de efeito estufa. ${ }^{11}$ No processo, adicionam-se de 10 a $20 \%$ de óleo vegetal ou gordura animal ao óleo diesel antes de sua passagem pelas unidades de hidrotratamento nas refinarias para reduzir o teor de enxofre. A reação ocorre em elevada pressão e temperatura, com a presença de catalisador metálico.

A hidrogenação direta de óleos com ou sem a presença de catalisadores do tipo Ni-Mo tem, também, sido desenvolvida especialmente pela NExBTL e British Petroleum. ${ }^{42,43}$ A hidrogenação seguida por isomerização tem sido desenvolvida pela ENI e UOP. ${ }^{44,45} \mathrm{O}$ processamento a partir de madeira pelo processo Carbo V tem sido desenvolvido pela Neste Oil e pela Choren que produz o Sundiesel. . $^{42,46}$

Os processos de $1^{\mathrm{a}}$ geração de biodiesel têm maior número de artigos e patentes (Figura 7B), focando especialmente nas catálises enzimática, heterogênea e bioprocessos, seguidos por catálise homogênea. No entanto, verifica-se uma alteração significativa em relação a 2006 quando se concentrava em homogênea. ${ }^{10}$

As patentes brasileiras (Figuras 7B e 8D) apresentam lacunas na apropriação de conhecimento da rota enzimática e lignocelulósica e se concentram nos processos de $1^{a}$ geração. A $2^{\mathrm{a}}$ geração também está presente com pirólise, alta pressão e processos a vácuo, tendo a pirólise ou craqueamento dos óleos vegetais sido bastante significativas em 2008 (Figuras 7B e 8D) em artigos e patentes, ${ }^{47}$ apresentando crescimento em relação a 2006. ${ }^{10}$ No entanto, a tecnologia apropriada por patentes no Brasil ainda se concentra muito na $1^{\text {a }}$ geração, precisando ser incentivadas as rotas da $2^{\mathrm{a}}$ geração com vistas a baratear os processos, descobrir novas rotas possíveis e, deste modo, desenvolver e apropriar a tecnologia a ser utilizada em futuro próximo.

Dispositivos (protótipos, equipamentos, acessórios etc.) para biodiesel quase não são patenteados no planeta (Figura 7A), o que é atribuído a serem utilizados os já existentes para outros processos. No entanto, no Brasil, estão sendo patenteados (Figura 8A e B) especialmente reatores, plantas e geradores de energia. ${ }^{48}$ Isto pode ser atribuído tanto à maior facilidade de elaboração de documentos de patente deste tipo, como à cultura de patenteamento ser mais facilmente disseminada entre profissionais diretamente envolvidos com a produção, estando ainda incipiente entre químicos, onde a cultura de publicação de artigos está mais disseminada e é exigida pelas instituições de fomento brasileiras.

Em dezembro de 2008, existiam no Brasil 62 plantas de biodiesel autorizadas para operação, 23 novas plantas em processo de autorização, 8 em processo de ampliação, sendo 2 autorizadas para comercialização de B100, totalizando a capacidade autorizada de $11.023,36 \mathrm{~m}^{3} / \mathrm{d}^{49}$ Dessas 62 plantas, 39 são da rota metílica, 18 das metílica e etílica, e 5 da etílica ( $3 \%$ da capacidade instalada), sendo 
que estas últimas não estão produzindo de forma regular. O estado do Mato Grosso se destaca com 22 plantas, seguido de São Paulo com 8, Minas Gerais com 5, Goiás e Rio Grande do Sul com 4, Paraná, Ceará e Bahia com 3, Pará, Roraima e Tocantins com 2, e Mato Grosso do Sul, Maranhão e Rio de Janeiro com 1.

A produção de biodiesel no Brasil aumentou de $736 \mathrm{~m}^{3} / \mathrm{d}$ em 2005 para $918.340 \mathrm{~m}^{3} / \mathrm{d}$ em 2008. Nove empresas foram responsáveis por $72 \%$ do total: Brasil Ecodiesel (18,8\%), Granol (12,0\%), Biocapital (7,5\%), ADM (6,2\%), Agrenco (6,0\%), Oleoplan $(6,0 \%)$, Caramuru $(5,7 \%)$, Petrobrás $(5,1 \%)$ e Fragil $(4,8 \%) .{ }^{49}$

As matérias-primas utilizadas nessa produção foram lideradas pelo óleo de soja (78\%), sebo (16\%) e algodão (2,5\%), evidenciando que o biodiesel produzido é essencialmente de agricultura não familiar (soja e sebo), o que é preocupante por comprometer o objetivo de melhoria do IDH. Caso o gargalo seja o volume da venda, uma oportunidade para os pequenos agricultores seria a produção e extração a frio do óleo com aproveitamento da torta para ração animal e venda do óleo bruto, ao invés de vender apenas as oleaginosas e/ ou as sementes. Trabalhos anteriores têm mostrado que cooperativas para produção de biodiesel são economicamente viáveis, se tiverem subsídios, sendo importante que as matérias-primas sejam diversificadas, já que a economia do biodiesel é extremamente volátil por depender fortemente do preço de mercado da matéria-prima e dos preços de outros combustíveis, como petróleo e gás natural, sendo considerados também os custos de capital, eletricidade e créditos de glicerina. ${ }^{50}$

No planeta existem no momento apenas 11 plantas em operação ou previstas até 2010 , utilizando a $2^{\mathrm{a}}$ geração de processos de produção de biodiesel, com hidrogenação e craqueamento, hidrogenação e isomerização e o processo Carbo V. No Brasil, existe apenas uma planta autorizada pela ANP, a da Petrobras que opera com o processo H-Bio.

\section{POLÍTICA DE ESTADO E RESPOSTA EMPRESARIAL}

No caso do Brasil, existe uma política de Estado firme e coerente iniciada em 2 de julho de 2003 com o Decreto Presidencial que instituiu um Grupo de Trabalho Interministerial (GTI) para viabilizar a utilização do biodiesel como fonte alternativa de energia e definir as ações necessárias, culminando com o lançamento oficial do Programa Nacional de Produção e Uso do Biodiesel (PNPB). ${ }^{4}$

$\mathrm{O}$ marco regulatório alicerça-se num tripé que respeita a energia, o ambiente e o social, potencializando a melhoria do IDH e a geração de PIB:

I - obrigatoriedade de autorização prévia para produção e uso, e clareza de especificação (Resoluções 41 e 42 da ANP, Nov/ 2004);

II - introdução do biodiesel na matriz energética brasileira de combustíveis líquidos e percentual anual aumentando gradativamente até no mínimo 5\% de biodiesel adicionado ao diesel para o consumidor final (Lei 11.097, de 13/01/2005 e subsequentes atos legislativos);

III - criação do selo combustível social promotor de inclusão social e gerador de emprego e renda, a ser concedido pelo Ministério do Desenvolvimento Agrário para empresas produtoras que priorizarem a aquisição de matérias-primas da agricultura familiar, assegurando como contrapartida benefícios tributários, acesso a linhas de financiamento e direito de concorrência em leilões de compra de biodiesel. Permite ainda que os agricultores familiares sejam sócios ou quotistas das indústrias extratoras de óleo ou de produção de biodiesel, de forma direta ou através de associações ou cooperativas de produtores (IN n ${ }^{\circ} 516$ da Secretaria de Receita Federal em 22/ fev/05, IN 02 do MDA de 30/set/05).

No Brasil, um fator decisivo para a implantação dos biocombustíveis foi a alta receptividade do empresariado e dos agricultores.
Aqui se destaca a Petrobras que, não apenas implementou as plantas produtoras de biodiesel com a tecnologia Crown de transesterificação, como também garante o fornecimento da matéria-prima ao incentivar o plantio, assegurando a compra do produto final. De fato, a Petrobras optou por formar parcerias com cooperativas, associações, sindicatos para organizar a produção, a logística e o treinamento. $\mathrm{O}$ programa alcançou tal magnitude que foi decidido criar a Petrobras Biocombustível, subsidiária integral da Petrobras, com a missão de fortalecer a atuação da Petrobras no segmento de biocombustíveis, viabilizando a cadeia produtiva e sendo responsável pelos projetos de produção de biodiesel e etanol. Espera-se que sua entrada no mercado possa contribuir significativamente para aumentar a participação da agricultura familiar e melhorar o IDH.

Paralelamente, a Petrobras tem expressiva contribuição no estímulo à geração de $\mathrm{C} \& \mathrm{~T}$ e $\mathrm{P} \& \mathrm{D}$, através do financiamento das suas Redes Temáticas, especialmente a de Rede de Revitalização de Campos Maduros que estuda o uso da GB para Recuperação Avançada de Petróleo (EOR), assim como a Rede de Desenvolvimento de Tecnologias para Combustíveis Limpos e a Rede de Desenvolvimento de Catálise. Também financiou os Núcleos Regionais, sendo que o da UFBA tem como um de seus seis eixos Combustíveis Fósseis e Provenientes de Biomassa. ${ }^{51}$

\section{CONDIÇÕES EDAFOCLIMÁTICAS NO BRASIL}

O clima brasileiro é adequado à plantação de oleaginosas para produção de biocombustíveis, sendo o solo adequado na maior parte do Brasil. No entanto, existe um gargalo sério que é a dependência de importações de fertilizantes, que em 2008 foi entre 70 e $90 \%$ do nitrogênio, fósforo e potássio. Torna-se assim uma oportunidade à P\&D\&I de novas formulações e recursos de fertilizantes.

O Brasil tem uma área total de 851 milhões de hectares, dividida em Floresta Amazônica (350 milhões de ha), pastagens naturais e cultivadas (220 milhões de ha), reservas legais (55 milhões de ha), lavouras anuais (47 milhões de ha), culturas permanentes (14 milhões de ha), plantações de florestas (5 milhões de ha), outras (20 milhões de ha), e área agricultável disponível (cerca de 90 milhões de ha). A esta última parcela pode-se acrescentar cerca de 60 milhões de hectares que atualmente são utilizados como pastagens e que, com o aumento da produtividade da pecuária brasileira passando do nível atual de aproximadamente 1 boi por hectare para um sistema mais produtivo, poderia atingir cerca de 0,8 boi por hectare, necessitando ainda de um pequeno acréscimo de tecnologia. No Brasil cerca de 7 milhões de hectares estão sendo ocupados com cana-de-açúcar, sendo cerca de metade para produção de etanol. A soja ocupa cerca de 22 milhões e o milho 13 milhões de hectares. ${ }^{52}$

As microalgas apresentam potencialidades tendo em vista várias vantagens em relação aos vegetais superiores. Sua multiplicação depende da fotossíntese, requerendo essencialmente $\mathrm{CO}_{2}$, água, luz solar e pequenas quantidades de sais minerais. Apresentam elevadas taxas de crescimento, além de outras características que tornam seu cultivo promissor para gerar matéria-prima para produção de biodiesel. As microalgas podem ser cultivadas em águas que são impróprias para o uso na agricultura, e podem utilizar efluentes de esgotos domésticos e industriais para a retirada de seus nutrientes. ${ }^{53}$

O cultivo das microalgas necessita de uma área muito menor do que aquela utilizada para produção agrícola. Uma estimativa mostra que podem ocupar apenas $1 \%$ da área que a soja utiliza hoje e produzir a mesma quantidade de biodiesel que ela produz. ${ }^{52}$ As microalgas são cultivadas principalmente para a finalidade de suplemento alimentar, uso em aquicultura e extração de produtos de alto valor comercial. Não existem cultivos em escala comercial com a finalidade de produção de biodiesel, desta forma não se tem informação sobre custos para este 
empreendimento. Todavia, todos os projetos até agora implantados apresentam altos custos de implantação e de produção da biomassa, que são superiores aos custos de produção das oleaginosas utilizadas em geral. Assim, um dos gargalos da produção de microalgas para a produção de biodiesel está no alto custo de produção, que pode ser diminuído com o aumento da produtividade em biomassa e óleo. Sendo eficientes fixadoras de $\mathrm{CO}_{2}$, seu uso tem ainda um impacto importante no sequestro de $\mathrm{CO}_{2}$ da atmosfera, deste modo fechando mais eficientemente o ciclo do carbono e contribuindo para a mitigação das alterações climáticas do planeta. No entanto, é ainda necessário estudar com cuidado a biocompetitividade e seus impactos no ecossistema. ${ }^{53}$

\section{MATÉRIA-PRIMA}

A matéria-prima é um dos principais pontos para produção de biodiesel e se deve levar em conta:

(a) o valor comercial relativo ao alto valor agregado de alguns tipos de óleo, podendo impactar nos preços finais do biodiesel; (b) o percentual de óleo no grão (Tabela 1) e a produção de grãos por área (Tabela 2); (c) a maximização do balanço energético entre a energia consumida no processo de produção e a energia disponibilizada pelo combustível produzido; (d) a vocação agrícola de cada região,

Tabela 1. Teor estimado de óleo e produtividade para diversas oleaginosas

\begin{tabular}{lccc}
\hline Oleaginosa & $\begin{array}{c}\text { Teor de Óleo } \\
(\% \mathrm{~m})\end{array}$ & $\begin{array}{c}\text { Produtividade } \\
(\mathrm{kg} / \mathrm{ha} \text { ano })\end{array}$ & $\begin{array}{c}\text { Produção } \\
\text { de Óleo } \\
(\mathrm{kg} / \mathrm{ha} \text { ano })\end{array}$ \\
\hline Mamona & 38 a 48 & 1500 & 720 \\
Girassol & 3542 & 1600 & 672 \\
Amendoim & 39 & 1800 & 702 \\
Gergelim & 39 & 1000 & 390 \\
Canola & 38 & 1800 & 684 \\
Dendê & 20 & 20000 & 4000 \\
Soja & 18 & 2200 & 396 \\
Algodão & 15 & 1800 & 270 \\
Babaçu & 6 & 12000 & 720 \\
Pinhão Manso & $35-45$ & $1000-6000$ & 500 a 2000 \\
Microalga & 20 & nd & 90.000 \\
\hline
\end{tabular}

Fonte: ref. 55. nd: não disponível.

Tabela 2. Produção de oleaginosas - safra 2007

\begin{tabular}{lccc}
\hline Oleaginosa & $\begin{array}{c}\text { Produção } \\
(\mathrm{t})\end{array}$ & $\begin{array}{c}\text { Rendimento } \\
\text { Médio (kg/ha) }\end{array}$ & $\begin{array}{c}\text { Área } \\
(\mathrm{ha})\end{array}$ \\
\hline $\begin{array}{l}\text { Algodão herbáceo } \\
\text { (caroço) }\end{array}$ & 4.094 .410 & 3.652 & 1.121 .288 \\
\hline Amendoim (em casca) & 227.249 & 2.216 & 102.557 \\
\hline Mamona (baga) & 88.574 & 576 & 153.850 \\
\hline Milho (em grão) & 51.830 .670 & 3.751 & 13.817 .340 \\
\hline Soja (em grão) & 57.952 .011 & 2.816 & 20.581 .334 \\
\hline Girassol (em grão) & 101.178 & 945 & 96.119 .100 \\
\hline Dendê (óleo) & 155.651 & 41.151 & 3.782 \\
\hline
\end{tabular}

Fonte: ref. 55 identificando a maior disponibilidade e menor custo de matéria-prima dentro da ampla diversidade de oleaginosas, que permite flexibilidade de produção; (e) a manutenção da produção de alimentos, priorizando a produção do biodiesel a partir das matérias-primas não alimentares ou OGR; (f) o baixo custo de produção e alta escala que pode levar a priorizar OGR em relação a óleos refinados ou reciclados.

Internacionalmente, o consumo de óleos vegetais para fins alimentícios é cerca de cinco vezes maior do que para fins industriais (Figura 9). Tanto no Brasil como na Índia, existe um número enorme de espécies produtoras de óleos adequados para biodiesel e que não são utilizados para alimentação. ${ }^{4}$ Assim, o risco da produção de biocombustíveis no Brasil competir com a produção de alimentos é baixo com referência ao mercado de óleos. No entanto, depende ainda da existência de resoluções apropriadas para o setor que, adicionalmente, inibam o desmatamento e a expansão desordenada em regiões inadequadas como a Floresta Amazônica e os cerrados.

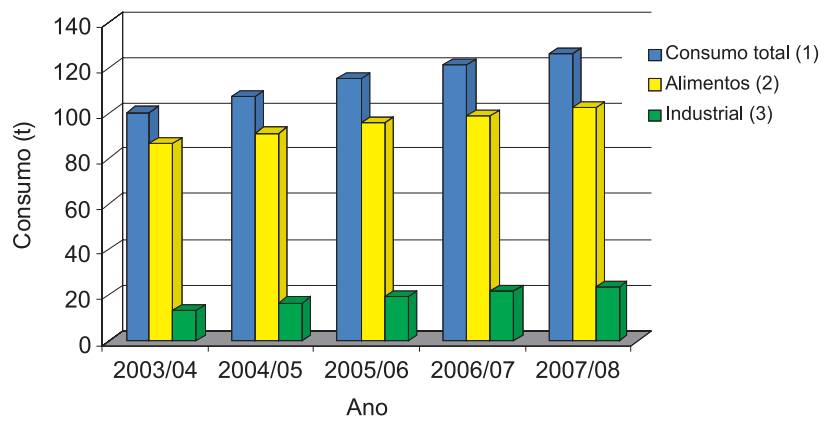

Figura 9. Consumo bianual mundial de óleos vegetais

De fato, a produção de biodiesel em nível internacional é refém de poucas culturas, sendo uma das preocupações da estratégia da comunidade européia para bioenergia. ${ }^{54} \mathrm{Na}$ Europa, a matéria-prima principal é o óleo de colza, cuja produtividade se situa entre 350 e $400 \mathrm{~kg}$ de óleo por hectare, tendo sido considerada satisfatória para as condições européias. O agronegócio da colza envolve a produção e comercialização do farelo, rico em proteínas, que corresponde a mais de $1.000 \mathrm{~kg}$ por hectare e, ademais, a sua lavoura promove uma excelente adubação natural do solo. ${ }^{54}$ Já nos EUA predominam o milho e a soja, que também são utilizados como produtos alimentares.

O Brasil apresenta um diferencial significativo, tendo diversidade de culturas que não competem com as de alimentação, terras agricultáveis, clima, solo, mão-de-obra, tecnologia e mercado interno crescente. No Brasil, existe grande diversidade de matérias-primas para a produção de biodiesel que incluem a mamona, o babaçu, a palma ou dendê, a soja, o algodão, o girassol, o amendoim e outras oleaginosas nativas que carecem ainda de muita pesquisa. ${ }^{55}$ Existem ainda perspectivas interessantes para algumas matérias-primas pouco citadas, entre elas o abacate, com uma produtividade estimada de $1.200 \mathrm{~L} / \mathrm{ha}$, porém sem culturas comerciais, e o pinhão manso. ${ }^{55,56}$ Atualmente, a maior parte do biodiesel é produzida a partir do óleo de soja por ser relativamente barato e já existir uma infraestrutura de produção bem estabelecida. ${ }^{49}$

A palma, de alta produtividade por área, inicia a produção a partir do quarto ano, atingindo a maturidade no sétimo ano, produzindo por mais três décadas. Sua colheita é artesanal, contemplando a agricultura familiar, e tendo alto teor de óleo, mas pode ser mecanizada com acontece na Ásia. ${ }^{55}$ Para a utilização do óleo de mamona, devido a sua alta viscosidade e acidez, tornou-se necessário misturar outros óleos de modo que o produto final seja especificado como, por exemplo, a mistura dos produtos oriundos da mamona e do girassol nos estados da Bahia e do Ceará. ${ }^{57}$ Uma das matérias-primas que desponta como grande potencial é o pinhão manso (Jartrofas curcas) 
pela rusticidade, produtividade e por se prestar de forma completa para a agricultura familiar. ${ }^{55}$

Analisando a Tabela 1, verifica-se que a produção de óleo por hectare é menor que $1.000 \mathrm{~L} / \mathrm{ha}$ ano para todas as culturas apresentadas. Porém, duas oleaginosas são diferentes, o dendê que pode ter cerca de $4.000 \mathrm{~L} / \mathrm{ha}$, e o pinhão manso para o qual são encontrados diversos dados, porém, não existe uma experiência longa com a cultura, podendo variar entre 1.000 e $3.000 \mathrm{~L} / \mathrm{ha}$. O pinhão manso tem vantagens em relação ao dendê por ser menos exigente com relação a solo, chuvas e clima, e não ser uma cultura alimentar. ${ }^{55}$

Os óleos encontrados nas microalgas possuem características físico-químicas e químicas similares aos de óleos vegetais e por isto elas podem ser consideradas como potencial matéria-prima para a produção de biodiesel e para querosene de aviação, pois produzem essencialmente dois tipos de moléculas utilizáveis, da mesma classe química, mas com tamanhos diferentes, tornando estas duas aplicações complementares. ${ }^{58} \mathrm{~A}$ extração do óleo pode ser realizada com solventes e estudos já mostraram que o rendimento de óleo depende da cultura e pode chegar a $85 \% .^{53}$ De modo geral, na composição de lipídios produzidos por microalgas encontram-se ácidos graxos tais como: C14:0 (mirístico), C14:1 (miristoléico), C16:0 (palmítico), C16:1 (palmitoléico), C18:0 (oléico), C18:2 (linoléico), C18:3 (linolênico) e C20:5 (eicosapenteneoico) $5^{53} \mathrm{~A}$ química brasileira poderia explorar mais efetivamente esta vertente com ações interdisciplinares em tanques de escala de demonstração.

O biodiesel de OGR dá melhor desempenho do motor e menos emissões reguladas em comparação com o diesel, no entanto, os produtos formados durante a fritura como ácidos graxos livres e alguns triacilglicerídeos polimerizados podem afetar a reação de transesterificação e, consequentemente, as propriedades do biodiesel de OGR.${ }^{59}$ Mais P\&D\&I são necessários para otimizar esta opção que ambientalmente tem grande interesse.

Existem diversas patentes e artigos referentes à extração do óleo (Figuras 7A e 8A). ${ }^{60} \mathrm{Em}$ geral, as patentes depositadas não especificam o tipo de óleo vegetal utilizado (Figura 7D), usando apenas o termo "óleo vegetal", sendo uma estratégia para ampliar o escopo da proteção. Existem ainda poucas patentes e artigos para óleos ou gorduras residuais (OGR) como os provenientes de frituras e de esgotos, o que pode ser atribuído a serem mais complexos de se estudar e processar, devido à acidez, resíduos e existência de material polimerizado.

Torna-se necessário o desenvolvimento de cultivares para aumentar o rendimento de óleo, a otimização de estratégias de plantio alternado para manuseio da terra, aumentando o rendimento do solo e evitando o desgaste, o plantio em associação ou rotativo, poupando o solo e a altura complementar de plantas para regular a exposição ao sol. ${ }^{61}$ A química de produtos naturais poderia intensificar sua ação em identificação dos produtos naturais das espécies brasileiras visando a produção de biodiesel.

Uma outra vertente de $P \& D \& I$ é a identificação de rejeitos de processos que possuam composição química adequada para serem utilizados como insumos, como farelo e casca de arroz, ${ }^{62}$ ou que possam passar por um pré-processo para depois poderem ser utilizados.

\section{ÁLCOOIS}

Os álcoois geralmente utilizados na reação de transesterificação são álcoois de cadeia curta (metanol, etanol, propanol, butanol), sendo mais usados etanol e metanol por seu preço, disponibilidade e rendimento reacional. A obtenção do biodiesel através da rota metílica, ${ }^{63}$ apesar de mais conhecida e consolidada, requer manipulação do metanol que é bastante tóxico e é obtido geralmente de matériaprima de origem fóssil. O etanol apresenta as vantagens de baixa toxidade, produzir biodiesel com maior índice de cetano e maior lubricidade, e ser $100 \%$ renovável.${ }^{64}$ No entanto, o etanol tem menor reatividade sendo que, para se conseguir rendimentos para produção de biodiesel similares ao da rota metílica é necessário o uso de um maior excesso de etanol, além de maiores tempos de reação e maiores temperaturas, podendo impactar de maneira significativa no custo de produção. Outros gargalos do etanol envolvem os gastos energéticos, devido à azeotropia, para desidratação do excesso de etanol usado na reação e para separação do etanol contido na GB. Estudos com etanol apontam para a possibilidade de uso de novos catalisadores, incluindo a catálise heterogênea, ${ }^{65}$ uso de energia de micro-ondas, ${ }^{66}$ ou ultrassônica, ${ }^{40}$ além do emprego de misturas etanol/metanol na reação de transesterificação. ${ }^{67}$ Adicionalmente, o Brasil apresenta uma clara vocação para o uso do etanol, uma vez que desenvolveu nas ultimas décadas, de modo contínuo e consistente, a competência tecnológica para sua produção com preços competitivos a partir da cana-de-açúcar.

Existem mais artigos do que patentes para a rota metílica do que etílica (Figura 7C), no entanto, uma quantidade expressiva de patentes refere-se a álcool em geral sem especificar qual o tipo de álcool, aumentando deste modo o escopo da proteção. No Brasil, existe ainda uma lacuna de patentes neste tema. Assim, torna-se necessária P\&D\&I que busque a superação das dificuldades técnicas de uso do etanol para obtenção do biodiesel.

\section{QUALIDADE E ESPECIFICAÇÃO}

As patentes brasileiras (Figura 8A) privilegiam qualidade, ${ }^{68}$ sendo o tema mais abordado e os artigos têm contribuição relevante em especificações (Figura 7A) ${ }^{69}$ De fato, as especificações impostas para um combustível estão associadas à capacidade de produção, bom desempenho dos motores e, aspectos ambientais e relacionados à saúde da população. A qualidade mínima é atingida obedecendo às especificações técnicas, que são legalmente estabelecidas por lei e que asseguram a uniformidade do combustível na produção. Podem ocorrer modificações nas características físico-químicas do combustível no transporte até aos postos finais de revenda, seja devido à degradação natural, manuseio ou estocagem inadequados, ou seja por adulteração. Dessa forma, estudos visando o acompanhamento e a melhoria da qualidade e dos métodos de sua análise são importantes para garantir a eficiência do combustível, minimizando os efeitos ambientais e os possíveis danos à saúde..$^{70,71}$

No Brasil, a Resolução ANP No 7 de 19/03/2008 estabelece a especificação do biodiesel que poderá ser adicionado ao óleo diesel comercializado pelos diversos agentes econômicos autorizados, sendo assim importante que sejam realizadas também a caracterização e o controle da qualidade de suas misturas com diesel, além do acompanhamento de reação e do desenvolvimento de normas técnicas ABNT/NBR.

As normas e os métodos analíticos preconizados pela ANP, apesar de gerarem resultados confiáveis, foram na sua maioria desenvolvidos na primeira metade do século passado e, em geral, requerem longos tempos de análise, são laboriosos e envolvem equipamentos caros e sofisticados, consomem grande quantidade de solventes e reagentes, além de terem sido desenvolvidos para a realidade do biodiesel produzido na América do Norte e Europa. ${ }^{70}$ Dessa forma, é importante o desenvolvimento de procedimentos alternativos para monitoramento da qualidade do biodiesel, visando métodos analíticos automatizados e que permitam monitoramento remoto em campo e ao longo de toda a cadeia produtiva, priorizando rapidez, simplicidade e baixo custo. Algumas das oportunidades de pesquisa se encontram em (1) propostas de procedimentos rápidos, de menor custo, em tempo real, não intrusivos e não destrutivos, como as diversas espectrosco- 
pias $^{72}$ e outros métodos de análises químicas, associados ou não à quimiometria, para monitoramento de adulterações, contaminações e acompanhamento da reação; (2) desenvolvimento de sistemas de análise em fluxo visando simplificação e automatização e, (3) substituição de solventes orgânicos e padrões organometálicos usados para a determinação de metais, visando procedimentos mais limpos e de menor custo.

Uma vez que existe no Brasil um grande potencial para produção de biodiesel a partir de diferentes matérias-primas, é importante também que as especificações evoluam de modo não só a atender às exigências ambientais e ao bom funcionamento e desempenho dos motores, mas também incluir as várias possibilidades de uso de matéria-prima. Aqui também é necessária a atuação em P\&D para subsidiar o governo com boa ciência e tecnologia brasileira.

\section{ADITIVOS E MISTURAS (BLENDS)}

Misturas ou blends de matéria-prima para a produção do biodiesel, de diferentes tipos de biodiesel, ou, ainda, de biodiesel com diesel em proporções que compensem e otimizem as propriedades do combustível têm se mostrado promissoras até $20 \%,{ }^{73}$ especialmente no que concerne à melhoria das propriedades lubrificantes, sendo que, após este montante, ocasionam problemas de manutenção. De fato, misturas já era um tema promissor em $2006,{ }^{10}$ com pronunciado número de artigos e poucas patentes e, em 2008 (Figura 7A), cresceu o número de artigos e de patentes, no entanto, os artigos ainda são percentualmente mais numerosos, configurando-se uma área promissora para patentes.

Tem-se também como oportunidade a pesquisa de novos aditivos que atuem na melhoria das propriedades combustíveis, como redução da formação de goma e da degradação oxidativa. ${ }^{22,74}$ Este tema é altamente promissor, carecendo ainda de P\&D básica e aplicada para atender à necessidade de especificação que é indispensável para comercialização dos combustíveis. De fato, tanto patentes como artigos são ainda muito poucos (Figura 7A).

O biodiesel pode também ser utilizado como aditivo para recuperação avançada de petróleo, no entanto, sua viabilidade econômica tem que ser analisada cuidadosamente. ${ }^{75}$

\section{ARMAZENAMENTO E ESTABILIDADE}

O biodiesel pode ser armazenado por até 6 meses sem uso de aditivos, sendo que tempos mais longos podem causar problemas como variação da viscosidade e perda de geração de energia, entre outros, podendo inclusive sofrer hidratação. ${ }^{76}$ Aqui é necessário continuar a desenvolver adsorventes como, por exemplo, argilas. ${ }^{28}$

Novos materiais, possivelmente inteligentes, são ainda necessários para obter tanques e recipientes que mantenham a qualidade do produto,${ }^{77}$ inibindo contaminação microbiana, reduzindo a presença de umidade e a oxidação, entre outros.

\section{EMISSÕES}

A queima de combustíveis fósseis, em fontes fixas ou móveis, tem contribuído significativamente para o aumento de poluentes na atmosfera. Esse acúmulo depende de fatores como constituição química do combustível, grau de mistura com oxigênio, temperatura, geometrias do injetor, queimador e câmara de combustão, entre outros. ${ }^{78}$ Assim, a combustão de biodiesel requer maior P\&D\&I para melhorar a sua eficiência, aumentar a durabilidade do motor e seus componentes e reduzir as emissões perniciosas. ${ }^{79}$

Teoricamente, hidrocarbonetos ao serem queimados nos motores de combustão interna deveriam produzir apenas $\mathrm{CO}_{2}$ e água. Porém, impurezas no combustível e deficiências no processo de combustão levam à formação de poluentes primários ( $\mathrm{CO}, \mathrm{NO}$, fumaça) e secundários (ozônio, nitrato de peróxiacetila - PAN, aldeídos etc.). Existem as substâncias que não causam danos à saúde, $\mathrm{CO}_{2}, \mathrm{H}_{2} \mathrm{O}, \mathrm{N}_{2}, \mathrm{O}_{2}$, e as que apresentam riscos à saúde e têm suas emissões regulamentadas, como $\mathrm{CO}, \mathrm{NO}_{x}, \mathrm{SO}_{x}$, material particulado, fumaça, entre outros. Adicionalmente, existem substâncias prejudiciais que ainda não foram regulamentadas como amônia, benzeno, cianetos, acroleína, aldeídos e hidrocarbonetos policíclicos aromáticos (HPA). ${ }^{78,80}$

Entre os principais problemas ambientais decorrentes das emissões prejudiciais, está o risco à saúde humana, aquecimento global, chuva ácida, danos à vegetação e às estruturas materiais com significativas perdas econômicas. ${ }^{81,82}$ Deve-se ainda destacar o smog fotoquímico, resultante da interação entre gases $\mathrm{NO}_{x}$, hidrocarbonetos e a luz solar, para formar produtos de oxidação que, em geral, são irritantes para os olhos e vias respiratórias. ${ }^{81}$

A queima do biodiesel e suas misturas emite menos gases regulamentados que a dos combustíveis derivados do petróleo, reduzindo significativamente os teores de hidrocarbonetos policíclicos aromáticos (PAHs), PAHs nitrogenados, fumaça e particulados em relação ao diesel, mas aumentando o teor de NOx, acroleina e formaldeído. ${ }^{6,83}$ No entanto, são ainda escassos os conhecimentos das emissões não reguladas e sua detecção. ${ }^{84}$

Aqui existem oportunidades tanto em monitoramento das emissões como em sequestro dessas emissões antes de serem liberadas para a atmosfera, como filtros, detectores, reciclagem etc.

\section{COPRODUTOS}

De modo geral, é usual se denominar de coprodutos o que tem mercado para venda, de subprodutos o que se vende se compensar economicamente, e de efluente o que é descartado e muitas vezes tem que ser tratado antes do descarte, dando prejuízo. No entanto, sob o ponto de vista da $\mathrm{P} \& \mathrm{D}$, todos podem ser considerados como coprodutos, pois necessitam ser reutilizados para reduzir os impactos ambientais e para maximizar os resultados da energia aplicada. Estes coprodutos podem agregar valor e se constituir em outras fontes de renda importantes para os produtores agrícolas e industriais, podendo consistir num fator para viabilizar a produção do biodiesel.

Como a transesterificação, especialmente a básica com catálise homogênea, é a mais pesquisada e utilizada, o foco será dado aos seus coprodutos, já que a magnitude do mercado de biodiesel introduz o desafio de identificar novos mercados e aplicações, pois sua produção aumentará bastante com o aumento da produção do biodiesel.

Os coprodutos sólidos são essencialmente de dois tipos: antes da prensa da oleaginosa, consistindo em resíduos de casca e matéria celulósica e, após a prensa, consistindo em farelo ou torta. Ambos costumam ficar com o pequeno produtor e ser queimados ou servir de repositório para o solo. No entanto, novas tecnologias estão sendo desenvolvidas, como a de hidrólise, para produzir etanol e promover a destoxificação da torta de mamona. ${ }^{85}$

O coproduto líquido é a glicerina bruta (GB) que consiste de uma mistura de glicerina, ácidos, ésteres, álcalis e álcoois, que era antigamente denominada genericamente como "glicerina" ou "glicerol". Seu grau de pureza é muito baixo, tendo a formulação típica de 40 a $90 \%$ de glicerina, 8 a $50 \%$ de água, menos de $2 \%$ de metanol e 0 a $10 \%$ de sais.

É essencial que os produtos gerados a partir dos coprodutos possam se inserir no mercado consumidor com boa relação custobenefício. Para isso se deve considerar o montante do valor agregado, o custo do preparo para a venda do coproduto para sua aplicação final, o tempo de lançamento do produto no mercado, a escala do mercado consumidor, os produtos concorrentes, entre outros. 
Na Tabela 3 estão listadas algumas das diversas aplicações dos coprodutos do biodiesel que se encontram disponíveis para o mercado ou em fase de desenvolvimento tecnológico. ${ }^{86-104} \mathrm{Cada}$ aplicação foi classificada quanto a dois critérios: (1) valor agregado, que avalia qualitativamente o valor que o mercado dá à aplicação final, dependendo da comparação com o preço de mercado de outros produtos similares; (2) qualitativo de custo preparativo, que consiste no custo necessário para preparar o coproduto para utilização direta na aplicação comercial, compreendendo a necessidade ou não de purificação, separação, reação química, modificação para geração de produtos correlatos etc.

A GB pode ser purificada, mas, se a uma quantidade expressiva da GB produzida for purificada e lançada no mercado, seu preço cairá significativamente e perderá boa parte de seu potencial para contribuir economicamente para viabilizar o biodiesel, além de poder desestabilizar o mercado da glicerina. Assim, tornam-se mais interessantes as aplicações com baixo custo preparativo. As aplicações de maior valor agregado são, sem dúvida, a injeção da GB para recuperação avançada de petróleo ${ }^{88}$ conforme estudo de viabilidade técnica e econômica, ${ }^{105}$ e a fabricação de materiais compósitos. ${ }^{74}$ No entanto, esta última dependerá ainda do setor da economia onde for aplicada.

O número de artigos e patentes referentes aos coprodutos é ainda relativamente pequeno (Figura 8A), sendo também um campo de ação portador de futuro. No Brasil (Figura 8C) as patentes concentram-se em glicerina e torta, estando presentes também outras. ${ }^{88,106}$

No caso de purificação, a glicerina pode ser classificada quanto à pureza como crua (75 a 90\% de glicerina), kosher e refinada, podendo esta última ter grau técnico ou industrial $(99,5 \%$ de glicerina); USP 99,5\%; USP 96\% (glicerina de origem vegetal); USP 99,5\% (glicerina de origem vegetal); USP/FCC - Kosher $99,5 \%$ e USP/FCC - Kosher $99,7 \%$. Na glicerina refinada devem ser observados pureza, cor, odor, conteúdo de ácidos graxos e de ésteres e conteúdo de cloretos.
A purificação da GB é feita em duas etapas: a pré-purificação, onde é transformada em glicerina crua, e a purificação propriamente dita, onde é transformada em glicerina técnica.

Na pré-purificação são removidos o álcool remanescente por aquecimento, os ácidos graxos e a água, obtendo-se glicerina com pureza de aproximadamente $80 \%$.

Na produção do biodiesel por catálise básica, boa parte da solução cáustica e do excesso de álcool usado no processo de biodiesel acumula-se na GB, junto com o sabão formado quando os ácidos graxos livres são neutralizados pelo excesso de álcali. A esta parte glicerínica podem ser adicionadas as águas acidificadas provenientes da lavagem dos ésteres para remoção de traços de catalisador, de sabões e de resíduos de álcool e glicerina. Nesta etapa é necessária $P \& D$ para encontrar métodos mais eficientes e com menos efluentes.

Na pré-purificação são produzidas três fases: I) na superfície, os ácidos graxos, II) no meio, a camada que deve ser separada e neutralizada, tornando-se glicerina crua, e III) no fundo, uma camada amarelada com algum precipitado parcialmente solúvel, contendo fósforo, fosfatos e catalisador, podendo os sais ser utilizados como fertilizantes, sendo este um tema potencial para P\&D. A camada de ácidos graxos pode ser reinserida no processo e sofrer uma reesterificação. ${ }^{107}$

Existem vários métodos para remover os ácidos graxos livres antes da transesterificação. Eles incluem separação dos ácidos graxos livres do óleo por lavagem cáustica, tratamento com vapor (steam stripping) e extração líquida. A grande desvantagem da lavagem caustica é o arraste também de óleo que pode ser de até duas vezes mais do que a quantidade de ácidos graxos livres no óleo. Esta também consiste numa área promissora para $\mathrm{P} \& \mathrm{D}$.

Os métodos tradicionalmente utilizados para purificação da glicerina crua são a destilação e a troca iônica. A destilação da glicerina crua tem como efluente o resíduo glicérico ou glicerina residual, que consiste em 10 a $15 \%$ em peso da GB inicialmente injetada, e

Tabela 3. Novas aplicações dos coprodutos

\begin{tabular}{|c|c|c|c|}
\hline Aplicação & Agregação de valor & Qualitativo de custo preparativo & Ref. \\
\hline Fabricação de compósitos & Alta & Baixa & 87 \\
\hline Recuperação avançada de petróleo & Alta & Baixa & 88 \\
\hline Fabricação de membranas poliméricas para células a combustível & Alta & Alta & 89 \\
\hline \multicolumn{4}{|l|}{ Adsorção de subprodutos da produção de biodiesel } \\
\hline catálise e dióis & Alta & Alta & 90 \\
\hline Aditivos para combustíveis & Média & Média & 91 \\
\hline Geração de energia por combustão & Baixa & Baixa & 92 \\
\hline Aditivos para fluidos de perfuração de poços de petróleo & Baixa & Média & 93 \\
\hline Síntese de polióis para produção de poliuretanas & Baixa & Média & 94 \\
\hline Geração de energia a partir do biogás gerado anaerobicamente & Baixa & Média & 95 \\
\hline Compostagem & Baixa & Média & 96 \\
\hline Produção de detergentes biodegradáveis por oxidação catalítica & Baixa & Alta & 97 \\
\hline Síntese de éteres & Baixa & Alta & 98 \\
\hline Produção de epicloro-hidrina & Alta & Alto & 99 \\
\hline Geração de hidrogênio para células combustíveis & Alta & Alto & 100 \\
\hline Aditivo de solos & Baixa & Alto & 101 \\
\hline Bioprodutos & Médio & Médio & 102 \\
\hline Gaseificação para geração de gás de síntese & Médio & Alto & 103 \\
\hline Obtenção de monômeros e solventes & Médio & Médio & 104 \\
\hline
\end{tabular}


requer ainda $\mathrm{P} \& \mathrm{D} \& \mathrm{I}$ visando viabilizar sua utilização. $\mathrm{O}$ processo de purificação por troca iônica tem alta eficiência, mas as resinas são extremamente caras, sendo importadas, e consistem no principal gargalo técnico, sendo também uma oportunidade em P\&D\&I.

A GB proveniente de catálise básica com $\mathrm{NaOH}, \mathrm{KOH}$ ou $\mathrm{NaOCH}_{3}$ apresenta desvantagens, pois os ácidos graxos livres consomem o catalisador na sua reação de neutralização, gerando sabões que dificultam a purificação da glicerina crua. A sua remoção por troca iônica aumenta o preço e reduz a eficiência da reciclagem do álcool e da produção da glicerina. Por exemplo, evaporadores de camada delgada não podem ser utilizados devido à sua presença.

A purificação por destilação consome mais energia, mas a flexibilidade é maior. Já a purificação da glicerina por troca iônica tem baixo consumo de energia e poucas etapas com operações mais simples. No entanto, a água deionizada não deve ter cloro, que é um veneno para as resinas de troca iônica.

\section{PERSPECTIVAS}

No caso do Brasil, deve estar sempre clara a existência de duas realidades sócio-econômico-ambientais bem diferentes que necessitam ser atendidas: as pequenas comunidades rurais remotas e as regiões com um nível mínimo de industrialização. No caso das comunidades rurais remotas, são necessários esforços de $\mathrm{P} \& \mathrm{D} \& \mathrm{I}$ para processos reativos robustos e confiáveis, mas que possam ser monitorados remotamente e, caso necessário, seja possível interferência remota do operador. Aqui se deve dar especial atenção ao sensoriamento à distância e a métodos de monitoramento rápidos e de baixo custo em tempo real, não intrusivos e não destrutivos. Adicionalmente, é necessário desenvolver processos para otimizar os esforços desses pequenos proprietários, típicos de agricultura familiar, como extração a frio de óleos, insumos disponíveis na região que atendam às condições edafoclimáticas, especialmente se forem produtos naturais, desenvolvimento de processo de reinserção na própria comunidade dos coprodutos e efluentes, e reatores e reações com alto rendimento e alta faixa de confiabilidade. Como o produto final é para uso próprio, a especificação não necessita atender obrigatoriamente às normas comerciais. Já em regiões industrializadas, passa a ser crucial a qualidade do produto e a relação custo-benefício.

Foi identificada no Brasil uma grande quantidade de inventores independentes que está iniciando a apropriação de suas descobertas e que poderia focar lacunas de P\&D\&I ainda não apropriadas por outros países, como as que requerem nanotecnologia. No entanto, a ação desses inventores deve ser encorajada pelo Estado, fazendo parte dos critérios de avaliação de produtividade, qualidade e mérito, para incorporar a cultura de apropriação de resultados de P\&D\&I sob a forma de patentes. As ICTs devem chegar mais perto de seus pesquisadores, visando reduzir os depósitos independentes, respeitando a Lei da Inovação (Lei 10.973, de 02/12/2004). É necessário também incorporar uma estratégia de investimento em recursos humanos e financeiros para depósitos de patentes internacionais tipo PCT.

A forte interação com empresas deve ser estimulada, aumentando o potencial da utilização da tecnologia desenvolvida, para que a inovação que gera PIB e IDH possa ocorrer e para que o Brasil possa concretizar seu potencial de liderança tecnológica neste tema. No entanto, as políticas públicas e os editais devem levar em conta a falta de uniformidade na distribuição das empresas brasileiras por estado e região do Brasil, devendo adequar as ações às realidades específicas.

O gargalo dos fertilizantes impacta desfavoravelmente não só no biodiesel, como nas demais plantações, sendo um dos problemas da autossuficiência do Brasil, devendo ter atenção especial. Seria bastante relevante avaliar a possibilidade da transformação de efluentes e subprodutos em fertilizantes.
Novas fontes de óleo, como as promissoras microalgas e o pinhão manso, e melhorias para o promissor dendê, são também desejáveis, necessitando ser focadas pelos pesquisadores. Se estas fontes forem de alta eficiência na retirada $\mathrm{CO}_{2}$ da atmosfera, passam também a ser importantes para mitigar as mudanças climáticas. É ainda importante o desenvolvimento de cultivares baseadas na ampla diversidade brasileira e adequadas a condições edafoclimáticas específicas. Podem ser estudadas misturas de vários óleos. É também interessante a micropropagação de oleaginosas não comestíveis para aumentar a oferta de mudas selecionadas para os novos plantios. É indispensável que as ações considerem o impacto na renda familiar rural e inibam o desmatamento e a expansão desordenada das culturas em regiões inadequadas. A vertente de aproveitar como matéria-prima subprodutos, efluentes e rejeitos de processos torna-se extremante atrativa por reduzir impactos ambientais negativos e contribuir para viabilizar outros processos e cadeias produtivas como, por exemplo, OGR, farelos e cascas.

A utilização de etanol ao invés de metanol seria de grande interesse, dada a capacidade produtiva do Brasil e o aumento do montante de bioinsumos. No entanto, é necessário P\&D\&I para aumentar o rendimento da reação e facilitar a separação da GB e a purificação do biodiesel.

Nos processos de $1^{\text {a }}$ geração é necessário melhorar a eficiência, os indicadores de impacto ambiental dos efluentes, a purificação de seus produtos com novos materiais, catalisadores mais eficientes e com menor impacto ambiental, materiais para equipamentos que sejam mais resistentes ao meio reacional. É necessário começar a atuar mais efetivamente nas áreas onde o Brasil não está atuando, como na catálise enzimática. Podem-se ainda desenvolver processos complementares para melhorar a eficiência durante a reação e separação. Os processos de $2^{\mathrm{a}}$ geração são altamente promissores, envolvendo a rota lignocelulósica, mas os investimentos devem ser realizados a médio e longo prazo, pois ainda é uma tecnologia embrionária que requer bastante $\mathrm{P} \& \mathrm{D} \& \mathrm{I}$.

Novos aditivos para conservação do biodiesel, quando estocado ou armazenado, e para uso em motores também são importantes.

No caso das emissões, é necessária ainda P\&D\&I para monitorar e modelar as reguladas e as não reguladas, até que existam modelos reprodutíveis e confiáveis para otimizar seu uso.

Os artigos e patentes brasileiras concentram-se em qualidade, seja de produtos e de insumos, seja de acompanhamento de reação, seja de especificação de biodiesel e de suas normas. Esta capacidade deve ser estimulada, podendo ser uma vertente de tecnologia a ser apropriada mais intensamente pelo Brasil.

Para a viabilização econômica e ambiental do biodiesel, é necessário o reaproveitamento de coprodutos (efluentes e subprodutos), seja com alto ou baixo custo preparativo, o que requer mais estudos. Novas rotas têm que ser desenvolvidas e para as existentes deve-se melhorar a qualidade, eficiência e relação custo/benefício.

Finalmente, é indispensável garantir o fôlego da cadeia produtiva do biodiesel nos próximos 10 a 20 anos de pesquisa e desenvolvimento tecnológico até que o Brasil atinja patamares mais favoráveis de viabilidade técnica e econômica, a exemplo do que o Brasil realizou com o etanol. Para isso, devem-se encorajar ações de curto prazo que sejam economicamente viáveis, como aplicações de coprodutos, especialmente os processos que apresentem altíssimo valor agregado e tenham baixíssimo custo preparativo como, por exemplo, a injeção de GB para recuperação avançada de petróleo e os materiais compósitos para a indústria automobilística.

Paralelamente, os pesquisadores/inventores devem ser estimulados a atingir o final da cadeia produtiva do conhecimento, ou seja, passar de pesquisa científica que gera os artigos, para o desenvolvimento tecnológico e a apropriação do conhecimento que gera as patentes, e para inovação que gera os produtos disponíveis no mercado. 


\section{AGRADECIMENTOS}

C. M. Quintella, E. A.Torres, L. S. G. Teixeira e M. G. A. Korn agradecem ao $\mathrm{CNPq}$ pelas bolsas de produtividade. P. R. C. Neto agradece à UTFPR pelo seu licenciamento e à Fapesb pela bolsa de pesquisador visitante. C. A. C. Jesus agradece à Fapesb pela bolsa de técnico.

\section{REFERENCIAS}

1. Garofalo, R.; OCL-Oleagineux Corps Gras Lipides 2002, 9, 299.

2. Ranganathan, S. V.; Narasimhan, S. L.; Muthukumar, K.; Bioresour. Technol. 2008, 99, 3975.

3. Pinto, A. C.; Guarieiro, L.; Rezende, M.; Ribeiro, N.; Torres, E.; Lopes, W. A; Pereira, P. A. P.; de Andrade, J. B.; J. Braz. Chem. Soc. 2005, 16, 1313.

4. Decretos $n^{\circ} 5.297$ de 6/12/2004 e no 5.457 de 6/12/2005; Suarez, P. A. Z.; Meneghetti, S. M. P.; Quim. Nova 2007, 30, 2068.

5. Pradhan, A.; Shrestha, D. S.; van Gerpen, J.; Duffield, J.; T. Asabe 2008, $51,185$.

6. Sharma, Y. C.; Singh, B.; Upadhyay, S. N.; Fuel 2008, 87, 2355; Castiglioni, R. F.; Abreu, F. R.; BR Pat. PI00160 2006

7. Mayerhoff, Z. D. V. L.; Cadernos de Prospecção 2008, 1, 7.

8. Oliveira, L. G.; Suster, R.; Pinto, A. C.; Ribeiro, N. M.; Silva, R. B.; Quim. Nova 2005. 28(Suplemento), S36.

9. www.inpi.gov.br/menu-esquerdo/informacao/alerta-tecnologico-1, acessada em Fevereiro 2009.

10. Jesus C. A. C.; Dissertação de Mestrado, Universidade Federal da Bahia, Brasil, 2008.

11. www.epo.org/patents/patent-information/raw-data/useful-tables.html, acessada em Dezembro 2008.

12. www.info.scopus.com/detail/what, acessada em Dezembro 2008.

13. www.thomsonreuters.com/products_services/scientific/Derwent_ Innovations_Index], acessada em Dezembro 2008.

14. Wimmer, T.; AT Pat. 198900023571989.

15. Castro, H. F.; BR pat. PI0306829 2003.

16. Neto, P. R. C.; Rossi, L. F. S.; Zagonel, G. F.; Ramos, L. P.; Quim. Nova 2000, 23, 531 .

17. Miyazaki, S. F.; Cadernos de Prospecção 2008, 1, 10; Souza, M. P.; Cadernos de Prospecção 2008, 1, 28; Curvelo, A.; Coutinho, D.; Cadernos de Prospecção 2008, 1, 30; Santos, F. N.; Pereira, T. S.; Cadernos de Prospecção 2008, 1, 22; Vinicio, E.; Suzarte, E.; Cadernos de Prospecção 2008, 1, 24; Cerqueira, G.; Rodrigues, P.; Cadernos de Prospecção 2008, 1, 38.

18. Brito Cruz, C. H.; Seminário Brasil em Desenvolvimento, IE, UFRJ, Rio de Janeiro, Novembro de 2003, disponível em http://www.ifi.unicamp. br/ brito/artigos/univ-empr-pesq-rev102003b.pdf acessada em Janeiro 2009.

19. v3.espacenet.com/eclasrch?locale=en_EP, acessada em Dezembro 2008.

20. www.inpi.gov.br, acessada em Dezembro 2008.

21. Santos, C. M. C.; Gonzalez, W. de A.; Velloso, M. H. R.; Borges, L.; BR Pat. PI04222 2006; Poli, D. M.; Muniz, J. P. A.; BR Pat. PI00781 2007; Ferrari, R. A.; BR Pat. PIO3386 2006; De Santis, E. J.; IT Pat. MIO2163 2004, WO Pat. EP11985 2005; Prehn, C. M. dos S.; BR Pat. PI00184 2007; Vieira, J. A. V.; Sabba, M.; Dias, B. S.; Ferreira, C. de A.; Menezes, S. M. C. de; BR Pat. PI03631 2005; Tomaz, A. J. G.; BR Pat. PI03453 2005; Paz, M. J. D.; Dabdoub, V. M. B.; Hurtado, G. R.; Batista, A. C. F.; Bortoleto, D. A.; BR Pat. PI02795 2005; Luxem, F. J.; Troy, W. M. US Pat. 0471272 P 2003, WO Pat. US13851 2004; Agnol, A. D.; Baldus, A. O.; Dariva, C.; Sobrinho, E. R. N.; Oliveira, J. V. de; BR Pat. PIO2891 2005; Aguiar, F. B. de; Figueira, A. C. B.; Covas, F. N.; BR Pat. PI03140 2004; Iijima, W.; Kobayashi, Y.; Taniwaki, Ken; JP
Pat. 0294521 2003, WO Pat. JP11485 2004; Silva, R. M. da; Farias, A. M. D. de; Gonzalez, W. de A.; Borges, L. E. P.; BR Pat. PI03904 2006; Lopes, O. C.; Maciel, A. J. da S.; BR Pat. PI03857 2006; Pereira, A. T.; Oliveira, K. A. de; Monteiro, R. de S.; Aranda, D. A. G.; Santos, R. T. P.; João, R. R.; BR Pat. PI00417 2005; Antunes, O. A. C.; Aranda, D. A. G.; BR Pat. PI00333 2005; Nakagaki, S.; Nunes, F. S.; Ramos, L. P.; Bail, A.; Vrubel, H.; BR Pat. PI05499 2006; Aranda, D. A. G.; Antunes, O. A. C.; Freire, D. M. G.; Lago, R. C. A.; Cavalcanti, E. D. A. C.; Sousa, J. S. de; BR Pat. PI03824 2006; Sato, S.; Almeida, W. B. de; Araujo, A. S.; WO Pat. BROO218 2004; Schuchardt, U. F.; Garcia, C. M.; Marciniuk, L. L.; Muterle, R. B.; BR Pat. PI00105 2006; Silva, R. D. de M.; BR Pat. PI06233 2004; Lopes, O. C.; Maciel, A. J. da S.; BR Pat. PIO2312 2005; Castiglioni, R. F.; BR Pat. PI03215 2005.

22. Ribeiro, N. M.; Pinto, A. C.; Quintella, C. M.; da Rocha, G. O.; Teixeira, L. S. G.; Guarieiro, L. L. N.; Rangel, M. C.; Veloso, M. C. C.; Rezende, M. J. C.; da Cruz, R. S.; de Oliveira, A. M.; Torres, E. A.; de Andrade, J. B.; Energy Fuels 2007, 21, 2433.

23. Ma, F.; Hanna, M. A.; Bioresour. Technol. 1999, 70, 1.

24. Hamelinck, C. N.; Faaij, A. P. C.; Energy Policy 2006, 34, 3268; Demirbas, A.; Energy Policy 2007, 35, 4661; Demirbas, A.; Progress in Energy and Combustion Science 2007, 33, 1.

25. Souza, A. G.; Danta, H. J.; Silva, M. C. D.; Santos, I. M. G.; Fernandes Jr., V. J.; Sinfrônio, F. S. M.; Teixeira, L. S. G.; Novák, C. S.; J. Therm. Anal. Cal. 2007, 90, 945.

26. Marchetti, J. M.; Miguel,V. U.; Errazu, A. F.; Fuel Process. Technol. 2008, 89, 740 .

27. Geris, R.; dos Santos, N. A. C.; Amaral, B. A.; Maia, I. D.; Castro, V. D.; Carvalho, J. R.; Quim. Nova 2007, 30, 1369; Rinaldi, R.; Garcia, C.; Marciniuk, L. L.; Rossi, A. V.; Schuchardt, U.; Quim. Nova 2007, 30, 1374 .

28. Silva, A. R. V.; Ferreira, H. C.; Revista Eletrônica de Materiais e Processos 2008, 3, 26; Cooke, B.; Abrams, C.; Bertram, B.; US Pat. 0509959P 2003, WO Pat. US32637 2004.

29. Narasimharao, K.; Lee, A.; Wilson, K.; J. Biobased Mat. Bioenerg. 2007, $1,19$.

30. Ferrari, R. A.; Oliveira, V. S.; Scabio, A.; Quim. Nova 2005, $28,19$.

31. Sprules, F. J.; Price, D.; US Pat. 2, 366-494 1950; Keim, G. I.; US Pat. 2, 383-601 1945.

32. Freedman, B.; Pryde, E. H.; Mounts, T. L.; J. Am. Oil Chem. Soc. 1984, 61, 1638; Mohamad, I. A. W.; Ali, O. A.; Bioresour. Technol. 2002, 85, 25.

33. Kawashima, A.; Matsubara, K.; Honda, K.; Bioresour. Technol. 2008, 99, 3439; Suarez, P. A. Z.; Meneghetti, S. M. P.; Meneghetti, M. R.; Wolf, C. R.; Quim. Nova 2007, 30, 667; Macedo, C. C. S.; Abreu, F. R.; Tavares, A. P.; Alves, M. B.; Zara, L. F.; Rubim, J. C.; Suarez, P. A. Z.; J. Braz. Chem. Soc. 2006, 17, 1291.

34. Suppes, G. J.; Dasari, M. A.; Doskocil, E. J.; Mankidy, P. J.; Goff, M. J.; Appl. Catal. A 2004, 257, 213.

35. Furuta, S.; Matsuhashi, H.; Arata, K.; Catal. Commun. 2004, 5, 721.

36. Foglia, T. A.; Nelson, L. A.; Marmer, W. N.; US Pat. 5713965, 1998.

37. Demirbas, M. F.; Balat, M.; Energ. Conver. Manag. 2006, 47, 2371.

38. Azcan, N.; Danisman A.; Fuel 2008, 87, 1781; Jermelovicius, L. A.; Senise, J. T.; Nascimento, R. B.; Castro, E. R.; Selmikaitis, A.; BR Pat. PI0604251 2006; Oglio, E. L. D.; Garofalo, M. N.; Souza, P. T. Jr.; BR Pat. PI0403530 2004; Portnoff, M. A.; Purta, D. A.; Pourarian, F.; Nasta, M. A.; Zhang, J.; BR Pat. PI0403235, US Pat. 200408676272004.

39. Guimaraes, W. G.; BR Pat. PI0601246 2006.

40. Georgogianni, K. G.; Kontominasa, M. G.; Pomonis, P. J.; Avlonitis, D.; Gergis, V.; Fuel Process. Technol. 2008, 89, 503.

41. www.biodieselbr.com/destaques/2006/h-bio-novo-diesel-petrobras.htm, acessada em Dezembro 2008; Gomes, J. R.; BR Pat. PI0500591 2005, US Pat. 186020 2006, EP Pat. 1693432 2005, AR Pat. P104823 2005.

42. www.nesteoil.com, acessada em Dezembro 2008. 
43. www.bp.com, acessada em Dezembro 2008.

44. www.eni.it, acessada em Dezembro 2008.

45. www.uop.com, acessada em Dezembro 2008.

46. www.choren.com, acessada em Dezembro 2008.

47. Soccol, C. R.; BR Pat. PIO6347 2004.

48. Machado, G. S. V.; Santos, F. C. de O.; BR Pat. PIO0307 2007; Lima, J. R. S. de; BR Pat. PI03891 2006; Batista, da S. A. M.; BR Pat. PI02721 2007; Geiger, H.; BR Pat. PI03599 2006; Sousa, M. A. F.; BR Pat. PI06268 2005; Prehn, K. G.; BR Pat. PI00575 2005; Neto, E. O. D. A.; BR Pat. PI05454 2006; Azevedo, A. L. A. de; Reboucas, R. do C. F.; BR Pat. PI04929 2004; Covalski, C. E.; BR Pat. MU02283 2006 ; Bonaventura, S. Di; BR Pat. PI02511 2006; Brun, G. S.; Silva, A. M. B. da; Oliveira, J. G. de; Piaia, E. A.; BR Pat. PI01772 2006; Cruz, A. B. de S.; Lopes, P. dos S. F.; BR Pat. PI00005 2006; Marchiori, A. M.; BR Pat. PI02536 2006; Pelly, M. F.; US Pat. $0456097 P$ 2003, WO Pat. US08294 2004; Batista, da S. A. M.; BR Pat. PI02391 2007; Belitardo, I. R.; Bento, F. R.; BR Pat. PI05024 2006; Covalski C. E.; BR Pat. MU02286U 2006

49. www.anp.gov.br/doc/biodiesel/Boletim_Mensal_de_Biodiesel_nov08. pdf, acessada em Dezembro 2008.

50. Bender, M.; Bioresour. Technol. 1999, 70, 81.

51. www.cienam.ufba.br/cienam.htm, acessada em Dezembro 2008.

52. Garcez, C. A. G.; Vianna, J. N. S.; Energy (2009), doi:10.1016/j. energy.2008.11.005, no prelo; Plano Nacional de Agroenergia 20062011, Ministério da Agricultura, Pecuária e Abastecimento, Secretaria de Produção e Agroenergia, Embrapa Informação Tecnológica, Brasília, DF, 2006, Brasil, www.embrapa.gov.br/publicacoes/institucionais/ agroenergia_miolo.pdf, acessada em Fevereiro 2009; Núcleo de Assuntos Estratégicos da Presidência da República do Brasil, Cadernos NAE - Processos estratégicos de longo prazo - Número 2/2005 Biocombustíveis, janeiro de 2005, NAE-Secom/PR, www.nae.gov.br/ cadernos_nae/02biocombustiveis.pdf, acessada em Fevereiro 2009.

53. Brown L. M.; Zeiler, K. G.; Energ. Convers. Manage. 1993, 34, 1005; Energy Products from Algae, www.oilgae.com/ref/report/ Preview_E_P_A.pdf, acessada em Fevereiro 2009; Teixeira, C. M.; Morales, M. E.; Anais do I Congresso da Rede Brasileira de Tecnologia do Biodiesel, Brasília, Brasil, 2006; Sheehan, J.; Dunahay, T.; Benemann, J.; Roessler, P.; A look back at the U. S. Department of Energy's Aquatic Species Program-Biodiesel from Algae, NREL/ TP-580-24190, Colorado, 1998, http://www.nrel.gov/docs/legosti/ fy98/24190.pdf, acessada em Fevereiro 2009; Huntley, M. E.; Redalje, D. G.; Mitigation and Adaptation Strategies for Global Change 2007, 12, 573; Câmara, G. M. S.; Heiffig, L. S.; Agronegócio de Plantas Oleaginosas: Matérias-Primas para Biodiesel, Universidade de São Paulo, Escola Superior de Agricultura "Luiz de Queiroz", Dep. de Produção Vegetal, Piracicaba: São Paulo, 2006; Teixeira, C. M. L. L.; Teixeira, P. C. N.; Rocha, H.; Almeida, A. G. de; Brito, G. F. C.; Anais do II Congresso da Rede Brasileira de Tecnologia do Biodiesel, Brasília, Brasil, 2007; www.agencia.fapesp.br/materia/9839/especiais/ biodiesel-feito-de-algas.htm, acessada em Dezembro 2008.

54. ec.europa.eu/energy/strategies/2008/2008_11_ser2_en.htm acessada em Fevereiro 2009; http://www.universoambiental.com.br/novo/artigos_ler. php canal $=7 \&$ canallocal $=12 \&$ canalsub2 $=34 \& \mathrm{id}=82$ acessada em Fevereiro 2009

55. Lourenço, S.; Boletim Agência FAPESP, http://www.agencia.fapesp. br/materia/9839/especiais/biodiesel-feito-de-algas.htm, acessada em Fevereiro 2009; www.nae.gov.br/cadernos_nae, acessada em Fevereiro 2009; www.pinhaomanso.com.br, acessada em Fevereiro 2009; www. ibge.gov.br, acessada em Novembro 2008; Costa, A.; I Seminário de Biodiesel do Estado do Paraná, Curitiba, Brasil, 2003; Torres, E. A.; Resumos do Encontro Nacional de Energia no Meio Rural, Campinas, Brasil, 2000.

57. www.fapesb.ba.gov.br/cti/noticias/noticia.2007-05-31.6495962521, acessada em Dezembro 2008; www.consecti.org.br/motix/pt_br/ destaques/Petrobras-inaugura-sua-primeira-usina-biodiesel,3670fd590d79-4752-a170-ce0a3992dd61.html, acessada em Dezembro 2008; da Cruz, R. S.; Almeida Neto, J. A.; Quintella, C. M.; Costa Neto, P. R.; Revista Bahia Análise \& Dados, submetido.

58. Huber, G. W.; Iborra, S.; Corma, A.; Chem. Rev. 2006, 106, 404; Schenk, P. M.; Stephens, E.; Posten, C.; Bioenergy 2008, 1, 20.

59. Kulkarni, M.G.; Dalai, A. K.; Ind. Eng. Chem. Res. 2006, 45, 2901.

60. Mello, L. M. B. da; BR Pat. PI01829 2006; Garcia, J. L.; BR Pat. MU00096U 2006; Houten, M. V.; Beaver, M. J.; Eyal, A. M.; Fox, E. J.; Ingvalson, J.; Jakel, N. T.; Kotowski, D. C.; Mcwilliams, P. J.; Patist, A.; Tupy, M. J.; Lohrmann, T. T.; US Pat. 0564202P 2004, US Pat. O628069P 2004, WO Pat. US12545 2005; Zappi, M.; French, W. T.; Hernandez, R.; Sparks, D.; Dufreche, S. T.; US Pat. 0507698P 2003, WO Pat. US32422 2004; Jorge, J. B.; Lazarini, L. H.; Domingues, C. A.; BR Pat. PIO2280 2006; Soares, J. E.; BR Pat. PIO2867 2006.

61. www.embrapa.br, acessada em Dezembro 2008.

62. Ju, Y. H.; Vali, S. R.; J. Sci. Ind. Res. 2005, 64, 866.

63. Milinsk, M. C.; Matsushita, M.; Visentainer, J. V.; de Oliveira, C. C.; de Souza, N. E.; J. Braz. Chem. Soc. 2008, 19, 1475.

64. Lima, J. R. D.; da Silva, R. B.; da Silva, C. C. M.; dos Santos, L. S. S.; dos Santos, J. R.; Moura, E. M.; de Moura, C. V. R.; Quim. Nova 2007, 30,600 .

65. Shibasaki-Kitakawa, N.; Honda, H.; Kuribayashi, H.; Toda, T.; Fukumura, T.; Yonemoto, T.; Bioresour. Technol 2007, 98, 416.

66. Perin, G.; Alvaro, G.; Westphal, E.; Viana, L. H.; Jacob, R. G.; Lenardão, E. J.; D’Oca, M. G. M.; Fuel 2008, 87, 2838.

67. Issariyakul, T.; Kulkarni, M. G.; Dalai, A. K.; Bakhshi, N. N.; Fuel Process. Technol. 2007, 88, 429.

68. Tenorio, J. M.; BR Pat. PI07064 2006; Sampaio, R. C. L.; Rodrigues, L. C.; BR Pat. PI04024 2005; Greenhill, S.; US Pat. 0436332 2002, WO Pat. 41050 2003; Banavali, R. M.; Stephens, R. W.; US Pat. 0765396, 2006, US Pat. 0786225 2006; Xavier, L. Jr.; Rodrigues, S. A.; Cardoso, J. C.; Soares, C. M. F.; Lopes, J. F.; Tupinamba, E. A.; Basmaji, P.; BR Pat. PI02332 2006; Petterle, F. R.; BR Pat. PI02083 2007; Souza, E. J. de; BR Pat. PIO3611 2006

69. Falate, R.; Nike, K.; da Costa Neto, P. R. D.; Cacao, E.; Muller, M.; Kalinowski, H. J.; Fabris, J. L.; Quim. Nova 2007, 30, 1677; Faria, R. C. M.; Rezende, M. J. C.; Rezende, C. M.; Pinto, A. C.; Quim. Nova 2007, 30, 1900; Froehner, S.; Leithold, J.; Lima Jr., L. F.; Quim. Nova, 2007, 30, 2016; Guarieiro, L. L. N.; Pinto, A. C.; de Aguiar, P. F.; Ribeiro, N. M.; Quim. Nova 2008, 31, 421; Rocha, D. D.; Barros, D. K.; Costa, E. J. C.; Souza, K. S.; Passos, R. R.; da Veiga, V. F.; Chaar, J. D.; Quim. Nova 2008, 31, 1062; Chaves, E. S.; Saint'Pierre, T. D.; dos Santos, E. J.; Tormen, L.; Bascunana, V. L. A. F.; Curtius, A. J.; J. Braz. Chem. Soc. 2008, 19, 856; Urioste, D.; Castro, M. B. A.; Biaggio, F. C.; de Castro, H. F.; Quim. Nova 2008, 31, 407.

70. Monteiro, R. M.; Ambrozim, A. R. P.; Lião, L. M.; Ferreira, A. G.; Talanta 2008, 77, 593.

71. Meher, L. C.; Sagar, D. V.; Naik, S. N.; Renewable \& Sustainable Energy Reviews 2006, 10, 248.

72. Guimarães, A. K.; Quintella, C. M.; Prêmio Petrobrás de Tecnologia, 2006; Guimarães, A. K.; Quintella, C. M.; BR Pat. PI000000 2009; Saul, C. K.; Aliske, M. A.; Veiga, W.; BR Pat. PI05856 2005; Sampaio, R. C. L.; Rodrigues, L. C.; BR Pat. PI04024 2005.

73. Sarin, R.; Sharma, M.; Sinharay, S.; Malhotra, R. K.; Fuel 2007, 86, 1365; Khalil, C. N.; Oliveira, M. C. K.; Ferreira, A. M. G.; BR Pat. PI05125 2004; Shahid, E.; Jamal, Y.; Renewable \& Sustainable Energy Reviews 2008, 12, 2484.

74. Barreto, A. J. B.; Mendes, D.; BR Pat. PI02633 2006; Modolo, D. L.; Avila, M. T. de; Feitosa, M. V.; Innocentini, M. D. de M.;BR Pat. PI01714 2005; Domingos, A. K.; Saad, E. B.; Vechiatto, W. W. D.; Wilhelm, H. M.; Ramos, L. P.; J. Braz. Chem. Soc. 2007, 18, 416. 
75. Silva, I. P. G.; Melo, M. A. de; Aguiar, A. de A.; Santana, A. P. S. C.; Mynssen, A. L. F.; Prates, V. R.; BR Pat. PI05371 2006.

76. www.biodiesel.gov.br/rede_arquivos/rede_publicacoes.htm, acessada em Dezembro 2008; Zerbi, N.; Tyson, K. S.; Biodiesel-Clean, Green Diesel Fuel, U.S. Department of Energy, DOE/GO-102001-1449, Fevereiro 2002; www.biodiesel.gov.br/rede_arquivos/armazenamentoII. htm, acessada em Novembro 2008; www.biodiesel.gov.br/rede_ arquivos/armazenamento.html, acessada em Novembro 2008.

77. Camargo, X. I. S.; BR Pat. PIO6456 2001.

78. Garcia, R.; Combustíveis e combustão industrial, Interciência: Rio de Janeiro, 2002.

79. Schäfer, F.; Basshuysen, R.; Reduced Emissions and Fuel Consumption in Automobile Engines, Springer-Verlag: Wien, New York, 1995.

80. Ferreira, S. L.; Santos, A. M.; Souza, G. W.; Polito, W. L.; Modolo, D. L.; Quim. Nova 2008, 31, 539.

81. Carmo, M.; Carvalho, M. F. A.; Quim. Nova 2003, 26, 265.

82. Wayne, R. P.; Chemistry of Atmospheres, $3^{\text {rd }}$ ed., Oxford University Press: Oxford, 2000.

83. Zhang, Y.; Boehman, A. L.; Energy Fuels 2007, 21, 2012; Guarieiro, L. L. N.; Pereira, P. A. D.; Torres, E. A.; da Rocha, G. O.; de Andrade, J. B.; Atmos. Environ. 2008, 42, 8211.

84. de Andrade, J. B.; Pereira, P. A. P.; Pinheiro, H. L. C.; Pat BR $M U$ 8501717-5 2005; de Andrade, J. B.; Souza, E. T.; Oliveira, F. S.; Pat BR MU 8601087-5 2006; Corrêa, S. M.; Arbilla, G.; Anais do I Congresso da Rede Brasileira de Tecnologia do Biodiesel, Brasília, Brasil, 2006.

85. Melo, W. C.; dos Santos, A. S.; Anna, L. M. M. S.; Pereira, N.; J. Braz. Chem. Soc. 2008, 19, 418.

86. www.biodiesel.gov.br/rede_arquivos/coprodutosII.htm, acessada em Novembro 2008.

87. Guimarães, J. L.; Satyanarayana, K. G.; Wypych, F.; Ramos, L. P.; Cursino, A. C. T.; BR Pat PIO605742 2006; Freitas, L. B. de; Mendes, L. M.; Castro Neto, P.; Fraga, A. C.; Araújo, J. C. de; Anais do II Congresso da Rede Brasileira de Tecnologia do Biodiesel, Brasília, Brasil, 2007; Guimarães, J.; Cursino, A. C. T.; Satyanarayana, K. G.; Ramos, L. P.; Sierakowski, M. R.; Wypych, F.; Anais do II Congresso da Rede Brasileira de Tecnologia do Biodiesel, Brasília, Brasil, 2007; Guimarães, J. L.; Satyanarayana, K. G.; Wypych, F.; Ramos, L. P.; Anais do I Congresso da Rede Brasileira de Tecnologia do Biodiesel, Brasília, Brasil, 2006.

88. Quintella, C. M.; Lima, A. M. V.; Musse, A. P. S.; Borges, S. M. S.; Almeida, P. M. M.; Torres, E. A.; BR Pat. PI0506358-2 2005; Borges, S. M. S.; Quintella, C. M.; Lima, A. M. V.; Musse, A. P. S.; Almeida, P. M. M.; Boletim técnico da Produção de Petróleo 2007, 2, 131; Borges, S. M. S.; Prêmio Petrobrás de Tecnologia (categoria Recuperação), 2005; Quintella, C. M.; Musse, A. P. S.; Borges, S. M. S.; Almeida, P. M. M.; Lima, A. M. V.; Guimarães, A. K.; SPE Journal, submetido. Borges, S. M. S.; Musse, A. P. S.; Lima, A. M. V.; Almeida, P. M. M.; Quintella, C. M.; Anais do II Congresso da Rede Brasileira de Tecnologia do Biodiesel, Brasília, Brasil, 2007.

89. www.cogeneration.net/polymer_electrolyte_membrane_fuel_cell.htm, acessada em Dezembro 2008.
90. Silva Sobrinho, N. A.; Dissertação de Mestrado, Universidade Federal de Pernambuco, Brasil, 2008.

91. Leitinho, J. L.; Nobre, K. A.; Feitosa, J. P. A.; Anais do $18^{\circ}$ Congresso Brasileiro de Engenharia e Ciência dos Materiais, Porto Galinhas, Brasil, 2008.

92. Almeida, C. H. T.; Amorim, H.; Castelletti, C. E. M.; Peres, S.; Anais do I Congresso da Rede Brasileira de Tecnologia do Biodiesel, Brasília, Brasil, 2006.

93. Yaakoub, M. C.; Rodrigues Jr., J. A.; Lachter, E. R.; Nascimento, R. S. V.; Anais do II Congresso da Rede Brasileira de Tecnologia do Biodiesel, Brasília, Brasil.

94. Arnaud, A. M. P.; BR Pat. PI0410530-3 2004.

95. Robra, S.; Santos, J. V. da S.; Oliveira, A. M. de; da Cruz, R. S.; Anais do I Congresso da Rede Brasileira de Tecnologia do Biodiesel, Brasília, Brasil, 2006.

96. Robra, S.; de Almeida Neto, J. A.; da Cruz, R. S.; Anais do I Congresso da Rede Brasileira de Tecnologia do Biodiesel, Brasília, Brasil, 2006.

97. Meira, J. A.; Camilios Neto, D.; Mitchell, D. A.; Ramos, L. P.; Krieger, N.; Anais do II Congresso da Rede Brasileira de Tecnologia do Biodiesel, Brasília, Brasil, 2007.

98. Pereira-Soares, V. L.; Silva, S. S.; Anais do II Congresso da Rede Brasileira de Tecnologia do Biodiesel, Brasília, Brasil, 2007; da Silva, C. R. B.; da Conceição, V. L. G.; Lachter, E. R.; Mota, C. J. de A.; Anais do II Congresso da Rede Brasileira de Tecnologia do Biodiesel, Brasília, Brasil, 2007.

99. www.in-pharmatechnologist.com/Materials-Formulation/Solvay-winsplaudits-for-renewable-epichlorohydrin-process, acessada em Dezembro 2008.

100. de la Piscina, P. R.; Homs, N.; Chem. Soc. Rev. 2008, 37, 2459.

101. Costa, F. X; Beltrão, N. E. de M.; Liv, S. S.; Guimarães, M. M. B.; Lucena, A. M. A. de; Anais do II Congresso da Rede Brasileira de Tecnologia do Biodiesel, Brasília, Brasil, 2007; Araújo, J. C. de; Fraga, A. C.; Castro Neto, P.; Anais do II Congresso da Rede Brasileira de Tecnologia do Biodiesel, Brasília, Brasil, 2007.

102. Santos, C. M. C. dos; Gonzalez, W. de A.; Anais do II Congresso da Rede Brasileira de Tecnologia do Biodiesel, Brasília, Brasil, 2007.

103. Xavier, D.; Valença, M. B.; Pascoal, E.; Medeiros, N.; Lucena, S.; Anais do II Congresso da Rede Brasileira de Tecnologia do Biodiesel, Brasília, Brasil, 2007.

104. Cardoso, R., V.; Gonçalves, V. L. C.; Rodrigues, R. C.; Mota, C. J. A.; Anais do II Congresso da Rede Brasileira de Tecnologia do Biodiesel, Brasília, Brasil, 2007.

105. Quintella, C. M.; Castro, M. P.; Bahia Análise de Dados, submetido.

106. Destefano, A. O.; BR Pat. PI03636 2007; Pradella, J. G. da C.; Rodrigues, M. F. de A.; Gomez, J. G. C.; Silva, E. S. da; Maiorano, A. E.; Carter, J. M.; Taciro, M. K.; Matsubara, R. M. S.; BR Pat. PI01139 2005; Guimaraes, J. L.; Satyanarayana, K. G.; Wypych, F.; Ramos, L. P.; Cursino, A. C. T.; BR Pat. PI05742 2006; Tranbol, B. S.; US Pat. 0955401 2004, WO Pat. US07462 2005; Ferro, A. A.; Rodrigues, R. C.; Machado, A. S.; BR Pat. 0110900000022009.

107. Boocock, D. G. B.; US Pat. 6399800, WO Pat. 01125812000. 